\title{
Prenatal stress alters progestogens to mediate susceptibility to sex-typical, stress-sensitive disorders, such as drug abuse: a review
}

\author{
Cheryl A. Frye ${ }^{1,2,3,4}$ *, Jason J. Paris ${ }^{1}$, Danielle M. Osborne ${ }^{1}$, Joannalee C. Campbell ${ }^{5}$ and Tod E. Kippin ${ }^{5}$ \\ 1 Department of Psychology, University at Albany-State University of New York, Albany, NY, USA \\ 2 Department of Biological Sciences, University at Albany-State University of New York, Albany, NY, USA \\ ${ }^{3}$ The Centers for Life Sciences, University at Albany-State University of New York, Albany, NY, USA \\ ${ }^{4}$ Neuroscience Research, University at Albany-State University of New York, Albany, NY, USA \\ ${ }^{5}$ Department of Psychology, University of California, Santa Barbara, CA, USA
}

Edited by:

Josephine Johns, University of North Carolina at Chapel Hill, USA

\section{Reviewed by:}

Elizabeth McCone Byrnes, Tufts University Cummings School of Veterinary Medicine, USA

Betty Zimmerberg, Williams College, USA

Deborah Ann Finn, Oregon Health \& Science University, USA

\section{*Correspondence:}

Cheryl A. Frye, Life Sciences 1049, The University at Albany-State University of New York, Albany, NY 12222, USA.

e-mail: cafrye@albany.edu
Maternal-offspring interactions begin prior to birth. Experiences of the mother during gestation play a powerful role in determining the developmental programming of the central nervous system. In particular, stress during gestation alters developmental programming of the offspring resulting in susceptibility to sex-typical and stress-sensitive neurodevelopmental, neuropsychiatric, and neurodegenerative disorders. However, neither these effects, nor the underlying mechanisms, are well understood. Our hypothesis is that allopregnanolone, during gestation, plays a particularly vital role in mitigating effects of stress on the developing fetus and may mediate, in part, alterations apparent throughout the lifespan. Specifically, altered balance between glucocorticoids and progestogens during critical periods of development (stemming from psychological, immunological, and/or endocrinological stressors during gestation) may permanently influence behavior, brain morphology, and/or neuroendocrine-sensitive processes. $5 \alpha$-reduced progestogens are integral in the developmental programming of sex-typical, stress-sensitive, and/or disorderrelevant phenotypes. Prenatal stress (PNS) may alter these responses and dysregulate allopregnanolone and its normative effects on stress axis function. As an example of a neurodevelopmental, neuropsychiatric, and/or neurodegenerative process, this review focuses on responsiveness to drugs of abuse, which is sensitive to PNS and progestogen milieu. This review explores the notion that allopregnanolone may effect, or be influenced by, PNS, with consequences for neurodevelopmental-, neuropsychiatric-, and/or neurodegenerativerelevant processes, such as addiction.

Keywords: addiction, alcohol, allopregnanolone, cocaine, dopamine, prenatal stress, serotonin, sex differences

\section{INTRODUCTION}

From the moment of conception, mothers provide a supportive environment for offspring development. Mother-fetus interactions during this period are largely mediated by hormonal communication. Progestogens, pro-gestational hormones, such as progesterone $\left(\mathrm{P}_{4}\right)$ and its $5 \alpha$-reduced $/ 3 \alpha$-hydroxylated metabolite, allopregnanolone (AlloP), may play an important role in developmental programming of offspring, which can have pervasive effects throughout the lifespan. How responses to specific challenges, during critical periods of development, alter the vulnerability or phenotype of offspring, and the potential mediation of AlloP, is the subject of this review. This review discusses findings regarding in utero maternal-offspring interactions via prenatal stress (PNS), which may influence drug effects and addiction, as well as other neurodevelopment-, neuropsychiatric-, and/or neurodegenerative-relevant processes in people and animal models. The emphasis on PNS and vulnerability to substance use and addiction may be one example of behavioral programming that can be influenced by pervasive changes in neuroendocrine milieu. The impact of PNS on addiction and drug effects is discussed. Next, how addiction-relevant brain circuits are changed by PNS is covered. Then, the role of stress and neuroendocrine regulation, as mediators of these effects are summarized. In particular, the role of progestogens, which mediate the stress axis and exert activating and/or organizing functions, are emphasized. The broader context and the role of AlloP mediating neurodevelopmental, neuropsychiatric, and/or neurodegenerative functions, that are relevant for drug abuse, are integrated. Thus, this review focuses on putative neuroendocrine mechanisms by which PNS may confer vulnerability to addiction and/or its related sequelae.

\section{IMPACT OF PRENATAL STRESS ON ANIMAL MODELS OF ADDICTION AND VULNERABILITY}

Prenatal stress increases the vulnerability to engagement in drug of abuse consumption. Several studies have revealed that PNS heightens the response to, and/or seeking of, stimulant drugs. Enhanced psychomotor activation in response to stimulants occurs in adult PNS male rats following challenge with amphetamine (Deminiere 
et al., 1992), cocaine (Kippin et al., 2008), or nicotine (Koehl et al., 2000), as well as in adolescent females (males were not examined in this report) following challenge with methylenedioxymethamphetamine (Morley-Fletcher et al., 2004). Further, greater behavioral sensitization has been observed in adult PNS males following repeated amphetamine injections (Henry et al., 1995) and in adult PNS females, but not males, following repeated cocaine injections (Thomas et al., 2009). Additionally, PNS appears to alter amphetamine-induced directional biases in adult female and male rats (Weinstock and Fride, 1989). Thus, PNS-induced changes in developmental programming impact subsequent psychomotor stimulant responses in both males and females, yet, PNS males may exhibit a more robust response to amphetamines.

Despite having different mechanisms of action, PNS can increase intake and seeking behavior of several drugs of abuse, including amphetamines, cocaine, and alcohol. Adult PNS male rats trained to self-administer amphetamine $(30 \mu \mathrm{l} /$ infusion, IV) or cocaine (escalating $0.3-0.5 \mathrm{mg} / \mathrm{kg} /$ infusion, IV) exhibit higher intakes, as well as response rates, relative to controls (Deminiere et al., 1992; Thomas et al., 2009). PNS may also influence the response to alcohol and increase alcohol-seeking behavior. Adult PNS rats show blunted effects of alcohol on autonomic measures, including body temperature, and behavioral measures (DeTurck and Pohorecky, 1987). Moreover, PNS consistently increases the intake and response rate during operant self-administration of alcohol in male mice (Campbell et al., 2009), while the impact of PNS on female intake and response rates is more variable (Campbell et al., 2010). Interestingly, sex differences have been observed in these effects. No effect of PNS was observed on the intake or response rates in females self-administering cocaine (escalating $0.3-0.5 \mathrm{mg} / \mathrm{kg} /$ infusion, IV), despite these animals exhibiting enhanced psychomotor stimulant sensitization compared to control females (Thomas et al., 2009). In comparison, another study (Kippin et al., 2008) using a higher, but constant, dose of cocaine $(1.0 \mathrm{mg} / \mathrm{kg})$, revealed a non-significant trend toward increased intake in PNS relative to control males. Moreover, these PNS males exhibited significantly greater responding under extinction conditions and greater cocaine-primed ( 5 and $10 \mathrm{mg} / \mathrm{kg}$ ) reinstatement of cocaine-seeking behavior compared to controls (Kippin et al., 2008). Further, observations of a PNS-induced blunted response to alcohol and an increased motivation for alcohol, resemble the widely supported observations that an initially blunted response to alcohol challenge is highly correlated with vulnerability to alcohol abuse and alcoholism development in humans (reviewed in Schuckit, 2009). Overall, the pre-clinical data indicate that PNS interacts with stress exposure and sex to impact subsequent drugseeking behavior to increase addiction vulnerability to a variety of drugs of abuse.

Given the divergent mechanisms of action between drugs of abuse, PNS may play a broader role to influence reward by perturbing targets and substrates that are important for pharmacological reinforcement. Indeed, PNS produces a variety of age-dependent alterations in cellular connectivity and plasticity in limbic-corticostriatal regions that may be associated with reward. PNS studies report decreased spine densities in CA1 and CA3 regions of the hippocampus among adult rats (MartinezTellez et al., 2009). Our own data demonstrate reduced synaptic spine density in dorsal hippocampus of adolescent (28- to 30day-old) rats exposed to variable PNS stressors (Paris and Frye, 2011b). The limbic system, comprising interconnected circuits in the cortex, amygdala, and hippocampus, along with the striatum and brainstem monoamine modulatory systems, appears to exhibit similar activation by reward and different classes of abuse drugs. Glutamatergic signaling, both between limbic structures and in projections to striatal and brainstem structures, are also widely implicated in reward and addiction processes (see, e.g., Gass and Olive, 2008; Kalivas et al., 2009; Volkow et al., 2010). PNS increases NMDA receptor binding in medial and dorsal prefrontal cortex (PFC), CA1, dorsal striatum (dSTR), and nucleus accumbens (NAcc), as well as, group III metabotropic glutamate receptor binding in both the medial and dorsal PFC (Berger et al., 2002; Barros et al., 2004). We have observed that PNS also decreases basal extracellular levels of glutamate measured by conventional microdialysis in the NAcc, but not in the PFC, of male rats (Kippin et al., 2008).

Prenatal stress also produces changes in the serotonin and norepinephrine monoamine systems throughout limbocorticostriatal circuitry. PNS increases serotonin and 5-HIAA total content in the dSTR (Gerardin et al., 2005) and PNS males, but not females, show significantly lower levels of 5-HT1A receptor binding in the ventral hippocampus (Van den Hove et al., 2006). PNS rats also exhibit decreased basal extracellular levels of serotonin measured by conventional microdialysis in the NAcc, but not in the PFC (Kippin et al., 2008). Conversely, basal levels of norepinephrine are lower in the NAcc of adolescent, but not adult, PNS rats (Silvagni et al., 2008) and in the PFC of both adult and adolescent PNS rats (Carboni et al., 2010). Given the roles of serotonin and norepinephrine in the regulation of dopamine systems and addiction (see, e.g., Goodman, 2008; Sofuoglu and Sewell, 2009), actions within these areas are widely believed to mediate the reinforcing properties of abused drugs, as well as play critical roles in addiction processes (reviewed in, e.g., McBride and Li, 1998; Lapish et al., 2006; Feltenstein and See, 2008; Koob and Volkow, 2010). Neuroplastic changes that are promoted by prolonged drug use may exert effects that are long-term and pervasive (Tindell et al., 2005). Within these reward circuits, PNS may also have pervasive effects to reduce the spine density of the medium spiny cells of the NAcc in adult, but not pre-adolescent, male rats (MartinezTellez et al., 2009). Thus, PNS has effects to alter the morphology and neurotransmitter activity of the rodent brain, which may have pervasive effects to influence reward responding throughout life.

Changes in neural structure and activity associated with PNS interact with drugs of abuse to influence their effects. In addition to PNS-induced changes under basal conditions, neurotransmitter responses are further altered with drug administration in PNS rodents. Cocaine-naïve and -experienced PNS males exhibit both greater dopamine and glutamate release in the NAcc, but not PFC, during acute cocaine challenge (Kippin et al., 2008). Acute amphetamine, but not nicotine, challenge produces greater dopamine release in the NAcc in both PNS adolescent and adult rats compared to controls (Silvagni et al., 2008), whereas amphetamine challenge also produces lower dopamine release in the PFC of adult PNS offspring (Carboni et al., 2010). Conversely, both amphetamine and nicotine challenge produced greater norepinephrine 
release in the NAcc of adult, but not adolescent, PNS rats (Silvagni et al., 2008). Amphetamine and nicotine challenge produced larger and smaller, respectively, norepinephrine release in the PFC of adult, but not adolescent, PNS rats (Carboni et al., 2010). Thus, PNS alters the circuitry mediating addiction-related behaviors in both drug-naïve and -experienced individuals under both basal and drug challenge conditions. However, the precise roles of these basal and drug-induced alterations to elevate drug-seeking behavior or drug-induced plasticity remain to be clarified. Moreover, how PNS alters natural reward processes is of interest.

\section{IMPACT OF PRENATAL STRESS ON ANIMAL MODELS OF NATURAL REWARD}

Natural rewards, as well as pharmacological rewards, via drugs of abuse, interact with PNS to affect the mesocorticolimbic and nigrostriatal dopamine systems. Actions of these systems are involved in providing incentive salience to stimuli and inducing, or maintaining, the performance of goal-directed behavior (e.g., Ikemoto and Panksepp, 1999; Salamone et al., 2009). The midbrain ventral tegmental area (VTA) is an important region involved in endogenously rewarding behavior and has been considered to be among the most important regions underlying pharmacological and natural reward (Nestler and Carlezon, 2006). The VTA receives glutamatergic inputs from the hippocampus, PFC, and amygdala, as well as monoaminergic inputs from the dorsal raphe, locus coeruleus, and hypothalamus and projects dopaminergic efferents to GABAergic neurons in the NAcc (reviewed in Nestler and Carlezon, 2006). Among rodents, engaging in mating is rewarding and can condition a place preference (Frye et al., 1998; Paredes and Vazquez, 1999; Meerts and Clark, 2007). In the VTA, actions at dopamine type 1-like receptors facilitate (while actions at dopamine type 2 -like receptors inhibit) mating in female rodents (Frye et al., 2004, 2006a; Sumida et al., 2005; Frye and Walf, 2008b). Dopamine is a necessary component involved in the motivational processes that facilitate mating among female rats (Becker et al., 2001). Some of these actions may be progestogendependent. Microinfusion of AlloP to the VTA enhances mating in female rodents in minutes (Frye et al., 2006a, 2008). Blocking D1 receptors attenuates AlloP's intra-VTA actions to enhance mating among female rats (Frye et al., 2004, 2006a). Indeed, PNS alters mating responses in adult female rats (Frye and Orecki, 2002) and increases total dopamine content in the dSTR (Gerardin et al., 2005), and NAcc (Alonso et al., 1994, 1997; McArthur et al., 2005). Notably, dopaminergic pharmacotherapy can bolster the motivational aspects of reward in animal models (Tindell et al., 2005).

Actions of AlloP in the VTA of the midbrain are profound and mediate goal-directed behaviors including those involved in natural reward, such as engagement in mating. For example, in adult female rats or hamsters, AlloP mediates approach and consummatory aspects of mating behavior, which are integral for conception to occur (Frye et al., 2006a). The proportion, intensity, and duration of lordosis responding (a stereotypical posture essential for mating behavior of rodents to occur) can be modulated by AlloP (Frye et al., 2006a). Midbrain dopamine cell bodies in the VTA project to limbic structures, including the amygdalar areas, hippocampus, and NAcc, as well as to areas of the PFC, and cell bodies in the substantia nigra innervate dSTR regions and other motor structures (reviewed in Haber and Fudge, 1997; Horvitz, 2000). Together, dopaminergic VTA projections makeup the mesolimbic dopamine system. Connections between the VTA and NAcc modulate the valence of pharmacological and natural reward and the motivation to engage rewarding stimuli (Koob and Le Moal, 2001; Kelley and Berridge, 2002; Wise, 2004). Investigation into the ability of AlloP, and other neurosteroids, to mediate altered neural function associated with heightened vulnerability to drug abuse (as well as other disorders) may lead to novel therapeutic avenues for the management of addiction-related problems. Thus, PNS alterations in levels of AlloP may partly mediate the lifelong alterations in the mesocorticolimbic dopamine system and perhaps other components of addiction circuitry involved in PNS-induced elevations of drug/alcohol-seeking behavior.

\section{PRENATAL STRESS-INDUCED ALTERATIONS IN NEUROCHEMISTRY AND ALLOPREGNANOLONE MAY BE ASSOCIATED WITH CHANGES IN ADDICTION-RELATED BEHAVIOR}

Prenatal stress influences the circuitry of addiction, as well as AlloP, in adulthood. Although direct evidence is not available, we hypothesize that these endpoints are functionally inter-related. Indirect support for this hypothesis stems from separate lines of research indicating that: (1) PNS impacts cortico-limbic circuitry and its midbrain monoamine modulatory systems; (2) PNS alters hormonal milieu, including levels of AlloP, in a sex-dependent fashion; (3) AlloP modulates drug/alcohol-seeking behavior; and (4) AlloP has direct effects on "addiction circuitry" that are behaviorally relevant.

\section{PRENATAL STRESS ALTERS ALLOPREGNANOLONE}

Prenatal stress can influence endogenous AlloP concentrations of rodents. There are several models of PNS that are used in rats, which typically involve applying stressful stimuli during gestational days (GDs) 17-21, which is a critical period of hippocampal development in rats. Psychological stress can involve exposing pregnant dams to either a chronic predictable stressor (such as restraint thrice daily for $45 \mathrm{~min}$ ), or chronic unpredictable stressors (including forced swim, restraint, cold exposure, overnight fasting, light, and social crowding). We have previously observed perinatal psychosocial stressors, such as early maternal separation, reduce the ratio of $\mathrm{P}_{4}$ to its $5 \alpha$-reduced metabolites, dihydroprogesterone (DHP), and AlloP, in whole brain of postnatal day 2 rats, and dysregulate DHP and AlloP formation in whole brain of postnatal day 9 rats (Kehoe et al., 2000). We have recently investigated similar effects among juvenile rats. Among male and female offspring (between 28 and 30 days of age), stress resulted in decreased maternal AlloP levels during gestation, and reduced cognitive performance among offspring in an object recognition task, compared to controls (Table 1). These data are in concordance with findings wherein perinatal isolation is observed to increase circulating concentrations of the stress hormone, corticosterone, concurrent with reduced whole brain AlloP in rats (McCormick et al., 2002). Together, these data support the notion that early developmental stress can result in programmatic changes in neuroendocrine status with later consequences for cognition. 
Table 1 | Summarized results (mean \pm SEM) adapted from recent prenatal stress (PNS) studies in our lab, which indicate the effects of PNS via psychological stress [exposure to physical restraint (restraint) or unpredictable variable stress (variable) which included forced swim, restraint, cold exposure, overnight fasting, light, and social crowding], immune challenge [exposure to lipopolysaccharide (LPS, $30 \mu \mathrm{g} / \mathrm{kg}$; dams only), or interleukin-1 $\beta$ (IL-1 $\beta, 1 \mu \mathrm{g} / \mathrm{rat})$ ], finasteride administration $(50 \mathrm{mg} / \mathrm{kg}$ ), or minimal handling/vehicle (control) on gestational days 17-21 ( $n=4-8$ dams/group; $n=17-30$ offspring/group) has on maternal/fetal allopregnanolone and dependent cognitive behaviors (object recognition performance) of male and female rats (data are collapsed on the variable of sex).

\begin{tabular}{|c|c|c|c|c|c|}
\hline $\begin{array}{l}\text { Challenge at } \\
\text { GD17-21 }\end{array}$ & How? & $\begin{array}{l}\text { Dams' plasma AlloP } \\
\text { at parturition } \\
\text { (ng/ml) }\end{array}$ & $\begin{array}{l}\text { Offspring (male and } \\
\text { female) Hippo } \\
\text { AlloP (ng/g) }\end{array}$ & $\begin{array}{l}\text { Novel obj } \\
\text { recognition (\% time } \\
\text { with Object) }\end{array}$ & Reference \\
\hline $\begin{array}{l}\text { Control (nothing, } \\
\text { vehicle) }\end{array}$ & $\begin{array}{l}\text { Handling, IP } \\
\text { Saline, SC oil }\end{array}$ & $2.2 \pm 0.8$ & $1.8 \pm 0.2$ & $53 \pm 4 \%$ & $\begin{array}{l}\text {-Paris and Frye (2011a,b), } \\
\text { Paris et al. (2011, under } \\
\text { review) }\end{array}$ \\
\hline $\begin{array}{l}\text { Psychological } \\
\text { (restraint, variable) }\end{array}$ & Thrice daily & $0.7 \pm 0.2^{*}$ & $1.0 \pm 0.4$ & $31 \pm 9 \%$ * & $\begin{array}{l}\text {-Paris and Frye (2011a), } \\
\text { Paris and Frye (2011b) }\end{array}$ \\
\hline $\begin{array}{l}\text { Immune (LPS-dams } \\
\text { only, IL-1 } \beta \text { ) }\end{array}$ & $\begin{array}{l}\text { LPS }(30 \mu \mathrm{g} / \mathrm{kg} \text {, } \\
\text { IP); IL-1 } \beta \\
(1 \mu \mathrm{g} / \text { day, IP) }\end{array}$ & $1.2 \pm 0.1^{*}$ & $1.5 \pm 0.6$ (IL-1 $\beta$ only) & $27 \pm 9 \% *$ (IL-1 $\beta$ only) & - Paris et al. (under review) \\
\hline $\begin{array}{l}\text { Endocrine } \\
\text { (finasteride) }\end{array}$ & $50 \mathrm{mg} / \mathrm{kg}$ & $0.5 \pm 0.3^{*}$ & $0.5 \pm 0.2^{*}$ & $22 \pm 7 \%$ * & •Paris et al. (2011) \\
\hline
\end{tabular}

*Indicates significantly different from control group, $p<0.05$.

\section{MECHANISMS OF PRENATAL STRESS: EVIDENCE FOR CRUCIAL INTERACTIONS BETWEEN GLUCOCORTICOIDS AND PROGESTOGENS}

There are pervasive effects of stress on developmental programming and functions throughout the lifespan; however, the mechanisms underlying these effects are not fully understood. There exists extensive evidence supporting a critical role for glucocorticoids in the programming effects of PNS, as well as, indications that glucocorticoids may be acting, in part, through alterations of other hormonal systems. We are interested in elucidating the extent to which AlloP may influence such responses through its actions on the stress axis. Changes in AlloP via PNS may be one mechanism by which PNS alters HPA axis-sensitive behaviors, such as drug use. Thus, findings regarding the stress axis and its interactions with AlloP on people, and in animal models, are summarized below.

\section{THE STRESS RESPONSE}

In response to acute stressors, there are changes in autonomic and neuroendocrine processes which may subserve adaptive behaviors. Irrespective of the type of stress experienced, the autonomic and neuroendocrine responses are ubiquitous and rapid. Catecholamines, epinephrine, and norepinephrine, heighten arousal by dilating pupils, increasing heart rate and respiration, and preparing for energy mobilization (reviewed in Wortsman, 2002). The sustained neuroendocrine response is mediated by the HPA axis. The HPA is comprised of the paraventricular nucleus (PVN) of the hypothalamus, the anterior pituitary (adenohypophysis), and the adrenals (reviewed in Turnbull and Rivier, 1997). The PVN synthesizes and releases corticotropin-releasing factor (CRF) to the adenohypophysis, where it promotes the release of adrenocorticotropic hormone (ACTH) into the periphery. ACTH stimulates the adrenal cortex to release glucocorticoids (i.e., cortisol in humans and corticosterone in most rodents), which have actions peripherally and centrally (reviewed in George and Koob, 2010).
Activation of these systems subserve behavioral responding (i.e., flight-or-flight) to acute stress, and may function to consolidate information surrounding salient events. Termination of the stress response occurs via negative feedback by glucocorticoid actions in the hypothalamus and pituitary (Herman et al., 1996) and also by AlloP (Patchev et al., 1994; Patchev and Almeida, 1996). Under chronic stress, the HPA feedback systems that typically act to restore (para)sympathetic tone are dysregulated and stressors may elicit a greater, lesser, or more prolonged HPA response than is typical.

Prenatal corticosterone exposure alone mirrors the effects of PNS on increased basal dopamine metabolism in both the dSTR and NAcc in male and female offspring (Diaz et al., 1995) suggesting that these processes may be influenced by HPA activation. Notably, PNS changes the expression and/or binding potential of dopamine D1 and D2 receptors, the dopamine transporter, as well as, the number of tyrosine hydroxylase-positive cells within the mesocorticolimbic dopamine system, including the NAcc, medial PFC, and hippocampal subregions (Alonso et al., 1994; Henry et al., 1995; Berger et al., 2002; McArthur et al., 2005; Son et al., 2007), which are important targets of the VTA (Nestler and Carlezon, 2006). As such, PNS may exert organizational effects to perturb the trajectory of the developing mesolimbic dopamine system. Indeed, perinatal stress (via early maternal separation) is observed to attenuate motor and dopamine responses to stress among adolescent rats (McCormick et al., 2002). Thus, there is evidence for PNS-induced changes in the structural and functional integrity of the dopamine reward circuitry among rodents.

\section{PROGESTOGEN MODULATION OF THE HPA AXIS RESPONSE}

There are differences in how females and males respond to stress and/or HPA activation, which may have bearing on the organizing effects of progestogens and/or responses to PNS. In response to stress, women typically have higher circulating cortisol 
levels and are more sensitive to glucocorticoid secretion than are men (Ellermeier and Westphal, 1995; Jezová et al., 1996; Ferrini et al., 1997; Hinojosa-Laborde et al., 1999; Rhodes and Rubin, 1999; Rohleder et al., 2001); however, females also demonstrate greater physiological and behavioral resiliency to negative/longterm effects of stress (Uno et al., 1989; Mizoguchi et al., 1992; Brown et al., 1996; Galea et al., 1997; Bowman et al., 2001, 2002; Beck and Luine, 2002; Conrad et al., 2003; Kitraki et al., 2004; McFadden et al., 2011). These sex differences in stress responding may be mediated by circulating levels of progestogens and/or their neurosteroid metabolites.

Progesterone, via actions of its metabolites, can suppress HPA axis activation. Progesterone can be $5 \alpha$-reduced to form DHP, which can be $3 \alpha$-hydroxylated to form the neuroactive metabolite, AlloP. Unlike progesterone and DHP, physiological concentrations of AlloP have little affinity for intracellular progestin receptors (Iswari et al., 1986). Rather, AlloP is a potent positive modulator of inhibitory $\mathrm{GABA}_{\mathrm{A}}$ receptors (Majewska et al., 1986), which may underlie its effects to dampen the HPA axis response (Purdy et al., 1991; Barbaccia et al., 1998). As such, it is progesterone's metabolism to AlloP, in response to stress, that promotes direct actions in hypothalamus to reduce CRF transcription and peptide precursors of the HPA mediated response (Patchev et al., 1994; Patchev and Almeida, 1996). These actions of AlloP partly underlie actions of progestogens to dampen HPA responsiveness in pregnancy; thereby, reducing fetal glucocorticoid exposure (Brunton et al., 2009). During pregnancy of people, the fetus can mount HPA responses by the second trimester, independent of the mother's HPA response (Gitau et al., 2001). Among female rats, PNS is associated with increased circulating corticosterone levels later in life (Walf and Frye, 2007). The extent to which stress-promoted maternal and/or fetal AlloP formation may account for physiological and behavioral stress phenotypes is of interest.

\section{ALLOPREGNANOLONE NORMALLY INHIBITS THE HPA AXIS RESPONSE TO STRESS DURING PREGNANCY}

AlloP's role in attenuating stress axis response extends to maintaining gestation, protection of the fetus, and/or possible organizing effects. Among pregnant women and rodents, circulatory AlloP is elevated throughout gestation and its decline precedes parturition (Concas et al., 1999; Gilbert-Evans et al., 2005; Paris and Frye, 2008). During early pregnancy, progestogens are secreted from the corpora lutea until the placenta becomes a source of progestogens (Concas et al., 1998). Circulating levels of $\mathrm{P}_{4}$ and AlloP co-vary and increase together during the first half of gestation. However, $\mathrm{P}_{4}$ levels decline prior to AlloP, later in pregnancy. Among rats, $\mathrm{P}_{4}$ levels peak between GD 10-15; whereas, AlloP asymptotes later in pregnancy (GD19; Concas et al., 1998) and declines to estrous levels around GD21 (Concas et al., 1998). During pregnancy, ACTH, corticosterone, and PVN CRF levels are lower, and oxytocin neurons are inhibited, such that stimuli that evoke a stress response in virgin rats do not elicit the same stress response in pregnant rats (Atkinson and Waddell, 1995; Johnstone et al., 2000; Brunton and Russell, 2003; Brunton et al., 2006a,b, 2005; Ma et al., 2005). In the developing offspring, central AlloP is observed as early as embryonic day 14 in rats (Kellogg and Frye, 1999), while postnatal AlloP increases in response to stressors on GD 6 (Kehoe et al., 2000; McCormick et al., 2002). Inhibiting AlloP formation with a $5 \alpha$-reductase inhibitor, finasteride, in late pregnancy restores HPA activation of ACTH, corticosterone, CRF, and oxytocin which can result in termination of pregnancy (Antonijevic et al., 2000; Brussaard and Herbison, 2000; Grobin and Morrow, 2001; Russell et al., 2003; Chanrachakul et al., 2005; Brunton and Russell, 2008a,b, 2010; Brunton et al., 2009). Thus, AlloP during gestation influences stress responding and gestational outcomes. Notably, administration of AlloP prenatally, counteracts the effects of PNS on anxiety-like tasks, indicating its role in neuropsychiatric-relevant behaviors (Zimmerberg and Blaskey, 1998).

AlloP during perinatal development may influence sex-typical differences in stress responding. We, and others, have utilized models of PNS in order to assess AlloP's developmental effects prior to parturition. Epidemiological studies of people, and experimental investigations using rodents, provide evidence that PNS can confer vulnerability to stress-related disorders that persist into adulthood. Behavioral and neurobiological aberrations associated with PNS may be sex-typical (i.e., predominant in one sex and/or related to changes in sex hormones), stress-sensitive (i.e., related to HPA activation and/or changes in stress hormones), and/or disorder-relevant (i.e., associated with the etiology or pathology of a neurodevelopmental, neuropsychiatric, and/or neurodegenerative disorder) functions. Although acute stress can be adaptive in adults through enhancing autonomic, neuroendocrine, and behavioral outputs that subserve species-typical adaptive responses (e.g., fight-or-flight), developmental stress can be pathological and detrimental to mothers and offspring. Typically, during late gestation, maternal stress responding is dampened. This stress hyporesponsive period, which is well-documented in rodents, may limit the deleterious developmental programming effects of PNS. The period of stress hyporesponsiveness coincides with elevations in AlloP (Paris and Frye, 2008; Brunton et al., 2009), which can be protective to the offspring (Frye and Bayon, 1998; Yawno et al., 2009), and dampen HPA axis reactivity (Patchev et al., 1994, 1996; Patchev and Almeida, 1996; Paris and Frye, 2008; Frye, 2009). There are PNS-induced alterations in neurosteroid levels which may play a direct role in programming the developing fetus (Kehoe et al., 2000; McCormick et al., 2002). This has led to our hypothesis that some effects of PNS may involve $5 \alpha$-reduced progestogens influence on developmental programming of sex-typical, stress-sensitive, and/or disorder-relevant phenotypes. Additionally, postnatal perturbation of maternal-infant interactions may have profound effects on stress responding and AlloP formation in offspring that are sex-dependent. We have found that maternal separation during postnatal days two through nine produces increases in central AlloP in offspring and these effects are greater in males (Kehoe et al., 2000). Thus, AlloP formation during early postnatal development may play an important role in programming of stress responses, and may present as a mechanism of PNS pervasive effects to influence drug reward and related sequelae.

\section{ALLOPREGNANOLONE INFLUENCES DRUG RESPONDING AND HAS POTENTIAL LINKS TO PRENATAL STRESS EFFECTS}

Pharmacological stimuli, such as drugs of abuse, activate the HPA robustly, as do the physical, psychological, and immune challenges 
described heretofore. We have presented evidence that PNS can alter responses to drugs of abuse, and that there are sex differences in response to PNS in these measures. Additionally, there is evidence consistent with the notion that PNS alters HPA function as well as AlloP levels, and that changes in AlloP can alter subsequent drug intake behaviors, also in a sex-dependent way. Causal relationships have not been established between perturbation of endogenous AlloP formation via PNS and later drug-seeking behavior. Rather, separate lines of research have revealed PNS to alter susceptibility to drug abuse/responding and AlloP formation in adolescence and adulthood. Adolescents are vulnerable to substance use, which is co-morbid with neuropsychiatric disorders and neurodegeneration. An important question for future investigation is what role progestogen formation may play in conferring vulnerability to natural or pharmacological reward. In support, progestogens, including AlloP, have been shown to modulate responding to many drugs of abuse. It is beyond the scope of this review to provide an in depth analysis of progestogen interactions with all drugs of abuse, such as depressants (i.e., alcohol), stimulants (i.e., cocaine, amphetamine, nicotine), and opiates. Thus, we focus on recent findings surrounding progestogens and drug abuse, and provide specific references for the complex interactions between AlloP and other steroid hormones with drugs, including alcohol and cocaine.

In addition to organizational effects of progestogens suggested by PNS, activational effects of progestogens are observed, which can differ across the sexes (another indication of potential organizing actions of hormones). There are sex differences in response to drugs of abuse, which may be partly mediated by progestogens and other sex steroids. Women are more likely than men to initiate drug use, demonstrate binge use, experience greater cravings, and relapse to greater use (Brady and Randall, 1999; Robbins et al., 1999; Mann et al., 2005; Gallop et al., 2007; Becker and Hu, 2008). Some evidence for hormonal mediation of drug use among pre-menopausal women is observed during cyclical hormonal fluctuations. In response to alcohol, women in the luteal phase (when circulatory progestogens are typically low) have increased positive effects of alcohol (Evans and Levin, 2011), decreased elimination, and blood alcohol clearance, which correlates with $\mathrm{P}_{4}$ levels (Sutker et al., 1987), lower AlloP levels (Nyberg et al., 2005), and feelings of anxiety and stress (Howell et al., 2010), the latter of which is co-morbid with cocaine use (Morton, 1999; Torres and Ortega, 2003; Poling et al., 2007; Rubin et al., 2007). In people, alcohol consumption decreases circulating $\mathrm{P}_{4}$ and AlloP levels in men (Pierucci-Lagha et al., 2006) and in women in the luteal phase (Nyberg et al., 2005). Nicotine effects, like alcohol, may vary based on hormone condition. During the luteal phase, number of cigarets smoked, nicotine craving, and positive subjective effects of smoking, increased in women (Mello et al., 1987; Snively et al., 2000; Franklin et al., 2004). Thus, low endogenous progestogen profile may yield vulnerability to alcohol's hedonic effects among naturally cycling women.

Animal models also show sex differences in substance use which may be influenced by hormonal milieu. Female rats and monkeys acquire, maintain, and escalate drug use, extinction, and reinstatement more readily than do males (see, e.g., Anker and Carroll, 2010). More targeted analyses have been conducted in rodents in response to alcohol that may be mediated by sex and duration of exposure. Notably, PNS can perturb hormone-sensitive behaviors across the estrous cycle of rats, which has been observed via reduced engagement in copulatory behaviors when rats are naturally sexually receptive (Frye and Orecki, 2002). When orally consumed, ethanol increased brain AlloP in male, but not female mice, an effect not observed when ethanol was injected (Finn et al., 2004). However, when alcohol is administered to facilitate alcohol-dependence, exposure may decrease cortical levels of AlloP in male, but not female, rats (Janis et al., 1998). As such, effects of alcohol on neurosteroid formation are biphasic and complex; a linear relationship between alcohol-enhanced neurosteroidogenesis and reward is unlikely. In support, cynomolgus monkeys that were trained to discriminate alcohol from water, demonstrated an enhanced ability to also discriminate AlloP when in the luteal (vs. follicular) phase of the menstrual cycle; however, cycle differences in discrimination were not observed for alcohol (Green et al., 1999). Neurosteroids, including $3 \alpha, 5 \alpha$-tetrahydrodeoxycorticosterone and $3 \alpha$-androstanediol, can be enhanced with alcohol administration and/or implicated in some alcohol effects (Paris and Frye, 2009; Serra et al., 2007. Indeed, AlloP and $3 \alpha$-androstanediol may promote hedonic effects in males, given that male rats will orally self-administer AlloP preferentially over water (Sinnott et al., 2002a), and male hamsters will orally self-administer $3 \alpha$-androstanediol over water (Frye et al., 2007). However, any effects that neurosteroid mechanisms may contribute to the reinforcing properties of alcohol are likely sex- and dose-dependent, given that AlloP injections have been observed to dose-dependently increase oral alcohol consumption among male, but not female, mice (Sinnott et al., 2002b). In addition to pregnane and androstane neurosteroids, estradiol may also contribute to sex differences to increase, while progestogens decrease, drug effects among females compared to males (Becker and Hu, 2008; Anker and Carroll, 2010). However, estradiol has been observed to not be altered in adult cycling female rats that have been exposed to PNS (Walf and Frye, 2007), which may suggest that it is a less likely mechanism for PNS-mediated changes in drug use. As such, there are complex interactions between sex hormones and many different drugs of abuse. These interactions may influence aspects of drugs abuse. For further review of alcohol's reinforcing interactions with AlloP (see Morrow et al., 2001; Finn et al., 2008; Helms and Grant, 2011). For evidence of other gonadal hormone contributions to alcohol's reinforcing effects (see Devaud et al., 2006).

Much research surrounding progestogens' effects on drug abuse have focused on cocaine. Autonomic, pleasurable effects, stressinduced cravings, and self-administration for cocaine are reduced when hormone levels are high in women during the luteal phase (Sofuoglu et al., 1999; Evans et al., 2002; Evans and Foltin, 2006; Sinha et al., 2007) and in rats during the proestrus phase (Hecht et al., 1999; Feltenstein and See, 2007). Administration of $\mathrm{P}_{4}$ to women attenuates subjective and HPA axis autonomic effects of cocaine and reduces craving (Sofuoglu et al., 2002, 2004; Evans and Foltin, 2006). Indeed, suppression of HPA axis responding following craving may be associated with some of cocaine's hedonic effects. Rodents will voluntarily self-administer either corticosterone (DeRoche et al., 1993) or AlloP (Sinnott et al., 2002a). 
We, and others, have found that $\mathrm{P}_{4}$ and AlloP levels of males and females are elevated in plasma, striatum, and hippocampus following cocaine administration, along with enhanced psychomotor behavior (Quinones-Jenab et al., 2008). Some of these effects may be dependent on estrous cycle phase, given that threshold for dose-dependent psychomotor activation to cocaine was increased among diestrous, compared to proestrus, female rats (Kohtz et al., 2010). Moreover, AlloP may influence some of cocaine's reinforcing effects. Pretreatment with AlloP diminishes escalating self-administration of cocaine in rats (Larsen et al., 2007; Anker et al., 2010). Progesterone reduced cocaine-primed reinstatement of cocaine-seeking behavior in female, but not male, rats and this effect was attenuated by finasteride and mimicked by AlloP administration (Anker et al., 2009). Although other gonadal hormones, such as estradiol have been investigated for their role on cocaine effects (for review see Segarra et al., 2009), it is $\mathrm{P}_{4}$ that has been utilized for clinical applications. Indeed, oral $\mathrm{P}_{4}$ has been investigated as a potential treatment for cocaine dependence (Reed et al., 2011); however, despite the need for further investigations, that study did not yield discriminating effects of $\mathrm{P}_{4}$ on self-administration. Therefore, drug effects and addiction behaviors that are increased by exposure to PNS, in particular, cocaine, are mediated by progestogens, including AlloP, which may indicate a possible mechanisms for further exploration into the neurodevelopmental impact and mechanisms of PNS on maternal-fetal interactions and later offspring behavior.

\section{NEURODEVELOPMENTAL, NEUROPSYCHIATRIC, AND NEURODEGENERATIVE SEQUELAE ASSOCIATED WITH PRENATAL STRESS AND/OR DRUG USE AND MAY BE PROGESTOGEN-SENSITIVE}

Neurodevelopmental, neuropsychiatric, and/or neurodegenerative disorders are co-morbid with drug use and are characterized by gender/sex differences and sensitivity to stress that may be influenced by progestogens. There is emerging consensus for similar neurobiological factors to underlie disorders that share similar features and/or endophenotypes. Thus, findings regarding the impact of gestational stress on people and animals, and the influence of progestogens in these processes, are summarized below.

\section{IMPACT OF PRENATAL STRESS ON DEVELOPMENTAL DISORDERS IN PEOPLE AND ANIMAL MODELS}

There are neurodevelopmental consequences of prenatal and perinatal stress that can be observed in juvenile (pre-pubertal) offspring. Despite the relative protection of the uterine environment, the fetus can be affected by environmental stressors that the mother experiences (Schlotz and Phillips, 2009). Like most stress challenges, in utero adaptation to environmental stressors may be an important aspect of organismal preparation for survival; however, enhancements in the chronicity, or saliency, of such stressors may also promote adverse effects. In people, PNS via chronic psychological and/or physical stress (such as those associated with low socio-economic status, poor coping skills, and maternal physical abuse) are associated with preterm birth and low birth-weight offspring (Facchinetti et al., 2007; Rodrigues et al., 2008; Giurgescu, 2009; Latendresse, 2009). Early birth under these conditions may lead to impairments in social, cognitive, and emotional behavior, which are observable when children are of school-age (Talge et al., 2010; Kerstjens et al., 2011; Lind et al., 2011). Among infants who are born preterm, there are also aberrations in cortico-limbic volume and/or sulci/gyri folding may be associated with neurodevelopmental disabilities, compared to antenatally age-matched controls (reviewed in Lodygensky et al., 2010). Moreover, the severity of premature birth may predict poorer neurodevelopmental outcomes (Talge et al., 2010). In addition to chronic stress, salient stress exposure during pregnancy can promote similar outcomes. After hurricane Katrina, over a two-fold increase in the incidence of preterm births was reported among pregnant women who were residing in a severely hit area, compared to those in less damaged areas (Xiong et al., 2008). Similarly, offspring born to women enlisted in the military that were deployed to a combat zone while pregnant, have a greater incidence of preterm birth and neurodevelopmental disorders, such as a major birth defect or malignancy (Ryan et al., 2011). Thus, chronic and/or salient PNS may promote neurodevelopmental disorder among people.

Prenatal stress exerts neurodevelopmental effects that can be modeled in rodents. In particular, the cortico-limbic brain regions may be a target for PNS. Compared to controls, pre-adolescent male rats that were born to dams that underwent physical restraint ( 2 h/day from GD 11 to birth), exhibited increased CA1, but decreased CA3, spine densities, while adult PNS male offspring had reduced spine densities in both areas (Martinez-Tellez et al., 2009). Long-term neurodevelopmental effects of PNS on the hippocampus may be particularly salient among females, given that a single exposure of PNS on GD18 can reduce adult dentate gyrus volume in female, but not male, rats (Schmitz et al., 2002). PNS is also observed to reduce spine density in PFC (Murmu et al., 2006; Michelsen et al., 2007). Over the course of development, the volumes of amygdalar sub-nuclei (an extension of the limbic system) tend to diverge among male PNS vs. control rats. By early adulthood PNS individuals may begin to match controls on some measures of nuclei volume (Kraszpulski et al., 2006), and may even surpass controls in the region of the lateral nucleus later in adulthood (Salm et al., 2004). The production of new neurons in the adult hippocampus is also reduced following PNS (e.g., Lemaire et al., 2000; Coe et al., 2003; Odagiri et al., 2008). Further, PNS or prenatal corticosterone treatment alter the levels of trophic factors and synapse-regulating proteins in limbic and cortical structures in an age-dependent fashion that may be responsible for the observed changes in dendritic spine densities (Fumagalli et al., 2004, 2005; Burton et al., 2007; Afadlal et al., 2010; Jutapakdeegul et al., 2010). Accordingly, these effects may have important consequences for early social and emotional development given the role of cortico-limbic function in regulating decision making and affect. In support, female PNS rats that are juvenile ( $\sim 30$ days of age) have increased anxiety-like behavior and decreased weight compared to control females (Baker et al., 2008). Male and female PNS juvenile offspring also show decreased social play behavior and reduced psychomotor activity (Kleinhaus et al., 2010). Additionally, PNS can affect male and female juvenile cognitive function in Y-maze, T-maze, and passive avoidance, the latter of which revealed females to have decreased performance compared to males (Gué et al., 2004). In rats, perinatal isolation has also been observed to worsen adult performance 
in the Morris water maze (Frisone et al., 2002). In people, this time period is equivalent to adolescence, which is characterized by the emergence of sex-typical, stress-sensitive behavioral disorders (i.e., autism, attention deficit hyperactivity disorder; McCormick and Mathews, 2007), novelty/drug seeking, and substance abuse (reviewed in Kroll, 2007; Bukstein, 2008). These findings suggest that aberrations in cortico-limbic brain regions may be present in adolescence and pervasive, at least until adulthood, following a history of PNS.

The HPA axis is activated in response to stressors, such as the physical and psychological stressors described above; however, one method to activate HPA axis activity in pregnancy is via immune challenge. This methodology is clinically relevant given that up to $40 \%$ of preterm births are associated with immune challenge/infection (Goldenberg et al., 2008). Administration of the bacterial endotoxin, lipopolysaccharide (LPS), or the cytokine, interleukin- $1 \beta$ (IL-1 $\beta$ ), in late gestation mimics infection/inflammation (Hermus and Sweep, 1990; Johnson et al., 1997; Turnbull and Rivier, 1999) and activates adrenergic synapses in the hypothalamus (Besedovsky and del Rey, 1992; Ericsson et al., 1994; Givalois et al., 1995; Turnbull et al., 1998; Brunton et al., 2005) and placenta (Paintlia et al., 2008). We have observed these regimens to reduce circulating AlloP in dams at the time of parturition (Table 1). Offspring that were gestationally exposed to immune challenge spent a significantly lower percentage of time with a novel object compared to controls (Table 1), which may indicate reduced cognitive performance. Given AlloP's importance in dampening HPA response during pregnancy, and the results from studies indicating decreased maternal AlloP following gestational stress (Frye and Walf, 2004; Paris and Frye, 2011a), we have investigated the necessity of maternal AlloP for these effects by administering finasteride $(50 \mathrm{mg} / \mathrm{kg})$ to dams in late gestation. Indeed, gestational finasteride produced similar effects to that of gestational stressors, resulting in reduced offspring cognitive behavior (Table 1). Notably, we have observed adolescent rats to spend less time with a novel object than do adult rats, irrespective of gestational manipulations. These data may imply a neophobic aspect to this task, that is not observed in adults, which may explain some of the aversion observed among adolescent rats exposed to gestational stressors (Paris and Frye, 2011a). These data support the notion that maternally derived $5 \alpha$-reduced steroids play an important role in the neurodevelopmental programming of lategestating offspring. This does not preclude finasteride interacting with other steroid hormones; given that finasteride also inhibits formation of androstane and glucocorticoid metabolites (reviewed in Finn et al., 2006) and further study of AlloP add-back will assess the ability of AlloP to rescue these effects.

Involvement of the HPA axis is further implied in studies of perinatal perturbation. Deficiencies in AlloP formation that are observed in plasma, via perinatal stress (lithium chloride injection), at 10 and 60 days of age are ameliorated by 90 days of age (Frye et al., 2006b). These data indicate that some perinatal reprogramming effects on the endocrine system may be transient; however, in these experiments, hippocampus AlloP remained perturbed at 60 and 90 days of age, suggesting that perturbation of central steroid formation may be pervasive throughout life (Frye et al., 2006b). These investigations imply that chronic HPA perturbation may be less severe in rodent models when manipulations occur later in development. An intriguing hypothesis for future consideration is that AlloP can have organizational effects in pre- or perinatal development which may be associated with its actions as a trophic factor throughout life. We have previously observed AlloP to be neuroprotective in rats, particularly when the HPA axis is perturbed (Rhodes et al., 2004). Thus, PNS can result in perturbed maternal and offspring AlloP levels and increased HPA responses, which may have effects on fetal neurodevelopment, neuropsychiatric-relevant behavior, and may reduce later neuroprotective capacity.

\section{IMPACT OF PRENATAL STRESS ON NEUROPSYCHIATRIC DISORDERS IN PEOPLE AND NEUROPSYCHIATRIC-RELEVANT BEHAVIOR IN RODENTS}

Among people, some findings suggests that stress during gestation may influence the etiopathology of neuropsychiatric processes. Those exposed to inordinate stressors during gestation, particularly during mid-gestation, are more likely to be diagnosed with schizophrenia, anxiety disorders, and depressive disorders (as reviewed in Bertram and Hanson, 2002; Matthews et al., 2002; Huizink et al., 2004; Seckl and Meaney, 2004; King, 2011). Children whose mothers experienced psychological stress during pregnancy show less social behavior, which is an early symptom of schizophrenia (Done et al., 1994). Adolescent children of women who had lost husbands during WWII while pregnant, suffered from higher rates of mood disorders and schizophrenia (Huttunen and Niskanen, 1978). There is also a significant correlation between the maternal experience of famine during the second and third trimesters and affective disorders in the adult children of those women (Brown et al., 2000).

Some of these effects may be due to perturbations in AlloP formation or actions. Women diagnosed with depression and/or premenstrual dysphoric disorder have decreased AlloP sensitivity (Freeman et al., 2002; Girdler and Klatzkin, 2007; Gracias et al., 2009) and do not experience the expected increase in AlloP following stress (Klatzkin et al., 2006). Women suffering from post-traumatic stress disorder (PTSD) have decreased AlloP levels in cerebrospinal fluid (Rasmusson et al., 2006). Men with PTSD, who have a greater psychological distress to trauma-relevant stimuli have lower levels of AlloP (Casada and Roache, 2004; Frye, 2009). Moreover, reduced $5 \alpha$-reductase activity (as determined by cortisol metabolism) was associated with symptom severity among individuals afflicted with treatment-resistant PTSD following the World Trade Center attacks in 2001 (Yehuda et al., 2009). Post-mortem brain AlloP levels were also decreased in a combined male/female sample of schizophrenic patients (Marx et al., 2006). As such, stress during human fetal development, and/or later chronic stress, may promote sex-typical, stress-sensitive disorders in adulthood, where AlloP varies with the incidence or expression of these disorders.

Findings from animal models suggest that PNS influences the developmental trajectory of neuropsychiatric-relevant function. Rodent models of PNS, specifically stress during late gestation, can produce behavioral sequelae later in life that were initially characterized by hyper-responsiveness to stressors. These responses have since been typified as maladaptive and/or early symptoms of behavioral disturbances. Offspring of PNS dams can 
be behaviorally inhibited, as is observed in response to maternal separation, wherein PNS pups vocalize and move less than do their non-PNS counterparts (Morgan et al., 1999). Male PNS juvenile rats demonstrate less social behavior and rough-and-tumble play than do control males (Ohkawa, 1987; Ward and Stehm, 1991). PNS increases anxiety-like behavior, indicated by spending less time on the open arms of an elevated plus maze (Fride et al., 1985; Zimmerberg and Blaskey, 1998) and/or more defecation in a novel environment (Wakshlak and Weinstock, 1990; Poltyrev et al., 1996; Vallée et al., 1997). PNS also increases depressive behavior, such as learned helplessness in the inescapable footshock paradigm, and increases anhedonia in the sucrose consumption model (Keshet and Weinstock, 1995; Secoli and Teixeira, 1998). Females, in particular, may be more vulnerable to some effects of PNS on depressive behavior as indicated by greater immobility in the forced swim test and less responsiveness to the anti-depressive effects of hormonal intervention, compared to their male counterparts (Drago et al., 1999; Frye and Wawrzycki, 2003). Aberrations in affective-like behavior may persist in female rats throughout life; adult females exposed to PNS demonstrate less struggling behavior (indicative of depression-like phenotype) in the forced swim test when pregnant (albeit not statistically significant), and significantly less struggling behavior when post-partum, compared to controls (Frye and Walf, 2004). While, it is not clear that AlloP formation/perturbation plays a role in the etiology of neuropsychiatric disorder, converging pre-clinical and clinical evidence support investigation of this premise, and provide evidence of the therapeutic efficacy of AlloP. For instance, AlloP add-back, concomitant with PNS, has been demonstrated to ameliorate, or reverse, anxiety-like behaviors produced by PNS (Zimmerberg and Blaskey, 1998). AlloP has demonstrated efficacy in improving neurodevelopmental disorders in mouse models of Niemann Pick disease (Mellon et al., 2008). Moreover, AlloP enhancement is associated with improvement in neuropsychiatric disorders, such as premenstrual dysphoric disorder among women (Freeman et al., 2002; Gracias et al., 2009).

\section{IMPACT OF PRENATAL STRESS ON NEURODEGENERATION IN ANIMAL MODELS}

Prenatal stress may promote neurodegenerative processes. Depression is associated with neurodegeneration in the hippocampus, concomitant with increased circulatory glucocorticoids (stress hormones), which may be facilitated by PNS. In adults, and rodent models, depression is associated with decreased neurogenesis in dentate gyrus and increased plasma glucocorticoid formation (Manji et al., 2001; Sapolsky, 2001). Early corticosterone exposure is necessary for dentate gyrus development of rodents and species-typical cognitive function (He et al., 2009) and glucocorticoid production from the adrenals promotes cell survival in the brain. Indeed, removal of the adrenals in rats increases cell death in the granule layer and dentate gyrus of the hippocampus (Frye and McCormick, 2000a,b; Rhodes et al., 2004). Moreover, co-administration of the $5 \alpha$-reductase inhibitor, finasteride, with $\mathrm{P}_{4}$ reinstatement attenuates these effects in ovariectomized females (Rhodes et al., 2004), suggesting that adrenally derived, $5 \alpha$-reduced progestogens have important trophic effects to maintain limbic integrity. These data support lines of research that utilize murine models of Alzheimer's disease. In support, APPswe + PSEN1 $\Delta$ e9 mice that present with central plaques and neurofibrillary tangles (an Alzheimer's disease-like phenotype) have decrements in hippocampally mediated behavioral tasks, compared to wild-type mice, and are deficient in their conversion of $\mathrm{P}_{4}$ to AlloP (Frye and Walf, 2008a). Thus, progestogens, such as AlloP, may have important trophic and neuroprotective effects throughout life.

Chronic stress exposure can promote neural degeneration (reviewed in Schoenfeld and Gould, 2011), as can exposure to a salient, acute stressors. For instance, a single episode of maternal restraint during a critical period for limbic development (GD18) reduces the number of granule cells in CA1-3 of adult female (but not male) offspring (Schmitz et al., 2002). Female PNS rats also exhibit age-dependent reductions in hippocampal neurogenesis (Koehl et al., 2009) and repeated maternal restraint, not only reduces the production of adult-born neurons, but also the number of adult neural stem cells (Kippin et al., 2004). These cells are critical for limiting the damage induced by central insults (Li et al., 2010). Thus, PNS effects may also promote later degenerative processes, and/or reduce proliferative processes, in the rodent brain, predisposing organisms to neurodevelopmental/affective disorder. Unfortunately, the greater incidence of morbidity and mortality among PNS offspring limits what is known about the influence of PNS on neurodegeneration throughout development. However, PNS is also notably associated with vulnerability to substance use and addiction. Indeed, adolescents are uniquely vulnerable to engagement in drugs of abuse, which is co-morbid with neuropsychiatric disorder and can promote/facilitate neurodegenerative processes. While, PNS can alter fetal programming of the neuroendocrine axis, altering AlloP formation, direct evidence for involvement of AlloP formation, via PNS, in the etiology of neurodevelopmental and/or neurodegenerative disorders is not clearly established. However, AlloP administration is associated with improvement in rodent models of neurodegenerative disorders including Alzheimer's disease (Wang et al., 2010), ischemic brain insult (Sayeed et al., 2006), and traumatic brain injury (Djebaili et al., 2005). Further, AlloP formation is perturbed in a mouse model of Alzheimer's disease and $\mathrm{P}$ administration improves cognitive performance (Frye and Walf, 2008a) and reduces depressive-like behavior (Frye and Walf, 2009) in a mouse model.

\section{CONCLUSION}

In conclusion, PNS may influence fetal programming, promoting vulnerability to drug seeking/use as well as some co-morbid neurodevelopmental, neuropsychiatric, and/or neurodegenerative disorders. These sequelae may be partly associated with secondary effects of PNS to alter natural reward processes, promoting vulnerability to substance abuse, and addiction. Thus, for its role in modulating drug salience, endogenous reward, developmental-, neuropsychiatric-, and neurodegenerative-relevant sequelae, AlloP remains an intriguing target for investigation. The extent to which regulation/actions of AlloP contribute to the etiopathophysiology of various sex-typical, stress-sensitive, neurodevelopmental, neuropsychiatric, and/or neurodegenerative disorders that have their origins in early puerperal, mother-infant interactions is an open and critical question. 


\section{ACKNOWLEDGMENTS}

This work was supported by funding from NIMH (MH06769801), NIAAA (INIA-Stress pilot project; U01AA01364-9), NIDA

\section{REFERENCES}

Afadlal, S., Polaboon, N., Surakul, P., Govitrapong, P., and Jutapakdeegul, N. (2010). Prenatal stress alters presynaptic marker proteins in the hippocampus of rat pups. Neurosci. Lett. 470, 24-27.

Alonso, S. J., Navarro, E., and Rodriguez, M. (1994). Permanent dopaminergic alterations in then accumbens after prenatal stress. Pharmacol. Biochem. Behav. 49, 353-358.

Alonso, S. J., Navarro, E., Santana, C., and Rodriguez, M. (1997). Motor lateralization, behavioral despair and dopaminergic brain asymmetry after prenatal stress. Pharmacol. Biochem. Behav. 58, 443-448

Anker, J. J., and Carroll, M. E. (2010). The role of progestins in the behavioral effects of cocaine and other drugs of abuse: human and animal research. Neurosci. Biobehav. Rev. 35, 315-333.

Anker, J. J., Holtz, N. A., Zlebnik, N., and Carroll, M. E. (2009). Effects of allopregnanolone on the reinstatement of cocaine-seeking behavior in male and female rats. Psychopharmacology (Berl.) 203, 63-72.

Anker, J. J., Zlebnik, N. E., and Carroll, M. E. (2010). Differential effects of allopregnanolone on the escalation of cocaine selfadministration and sucrose intake in female rats. Psychopharmacology (Berl.) 212, 419-429.

Antonijevic, I. A., Russell, J. A., Bicknell, R. J., Leng, G., and Douglas, A. J. (2000). Effect of progesterone on the activation of neurones of the supraoptic nucleus during parturition. J. Reprod. Fertil. 120, 367-376.

Atkinson, H. C., and Waddell, B. J. (1995). The hypothalamicpituitary-adrenal axis in rat pregnancy and lactation: circadian variation and interrelationship of plasma adrenocorticotropin and corticosterone. Endocrinology 136, 512-520.

Baker, S., Chebli, M., Rees, S., Lemarec, N., Godbout, R., and Bielajew, C. (2008). Effects of gestational stress: 1. Evaluation of maternal and juvenile offspring behavior. Brain Res. 1213, 98-110.

Barbaccia, M. L., Concas, A., Serra, M., and Biggio, G. (1998). Stress and neurosteroids in adult and aged rats. Exp. Gerontol. 33, 697-712.

Barros, V. G., Berger, M. A., Martijena, I. D., Sarchi, M. I., Pérez, A. A., Molina, V. A., Tarazi, F. I., and Antonelli,
M. C. (2004). Early adoption modifies the effects of prenatal stress on dopamine and glutamate receptors in adult rat brain. J. Neurosci. Res. 76, 488-496.

Beck, K. D., and Luine, V. N. (2002). Sex differences in behavioral and neurochemical profiles after chronic stress: role of housing conditions. Physiol. Behav. 75, 661-673.

Becker, J. B., and Hu, M. (2008). Sex differences in drug abuse. Front. Neuroendocrinol. 29, 36-47.

Becker, J. B., Rudick, C. N., and Jenkins, W. J. (2001). The role of dopamine in the nucleus accumbens and striatum during sexual behavior in the female rat. J. Neurosci. 21, 3236-3241.

Berger, M. A., Barros, V. G., Sarchi, M. I., Tarazi, F. I., and Antonelli, M. C. (2002). Long-term effects of prenatal stress on dopamine and glutamate receptors in adult rat brain. Neurochem. Res. 27, 1525-1533.

Bertram, C. E., and Hanson, M. A. (2002). Prenatal programming of postnatal endocrine responses by glucocorticoids. Reproduction 124, 459-467.

Besedovsky, H. O., and del Rey, A. (1992). Immune-neuroendocrine circuits: integrative role of cytokines. Front. Neuroendocrinol. 13, 61-94.

Bowman, R. E., Ferguson, D., and Luine, V. N. (2002). Effects of chronic restraint stress and estradiol on open field activity, spatial memory, and monoaminergic neurotransmitters in ovariectomized rats. Neuroscience 113, 401-410.

Bowman, R. E., Zrull, M. C., and Luine, V. N. (2001). Chronic restraint stress enhances radial arm maze performance in female rats. Brain Res. 904, 279-289.

Brady, K. T., and Randall, C. L. (1999). Gender differences in substance use disorders. Psychiatr. Clin. North Am. 22, 241-252.

Brown, A. S., van Os, J., Driessens, C., Hoek, H. W., and Susser, E. S. (2000). Further evidence of relation between prenatal famine and major affective disorder. Am. J. Psychiatry 157, 190-195.

Brown, L. L., Siegel, H., and Etgen, A. M. (1996). Global sex differences in stress-induced activation by 2-deoxyglucose autoradiography. Horm. Behav. 30, 611-617.

Brunton, P. J., McKay, A. J., Ochedalski, T., Piastowska, A., Rebas, E., Lachowicz, A., and Russell, J. A. of cerebral metabolism revealed

(DA077525; DA027115), NSF (IBN03-16083; IOS-0957148), and the National Alliance for Research on Schizophrenia and Affective Disorders.

(2009). Central opioid inhibition of neuroendocrine stress responses in pregnancy in the rat is induced by the neurosteroid allopregnanolone. J. Neurosci. 29, 6449-6460.

Brunton, P. J., Meddle, S. L., Ma, S., Ochedalski, T., Douglas, A. J., and Russell, J. A. (2005). Endogenous opioids and attenuated hypothalamic-pituitary-adrenal axis responses to immune challenge in pregnant rats. J. Neurosci. 25 5117-5126.

Brunton, P. J., and Russell, J. A. (2003). Hypothalamic-pituitary-adrenal responses to centrally administered orexin-A are suppressed in pregnant rats. J. Neuroendocrinol. 15, 633-637.

Brunton, P. J., and Russell, J. A. (2008a). Attenuated hypothalamo-pituitaryadrenal axis responses to immune challenge during pregnancy: the neurosteroid opioid connection. $J$. Physiol. 586, 369-375.

Brunton, P. J., and Russell, J. A. (2008b). Keeping oxytocin neurons under control during stress in pregnancy. Prog. Brain Res. 170, 365-377.

Brunton, P. J., and Russell, J. A. (2010). Prenatal social stress in the rat programmes neuroendocrine and behavioural responses to stress in the adult offspring: sex-specific effects. $J$. Neuroendocrinol. 22, 258-271.

Brunton, P. J., Sabatier, N., Leng, G. and Russell, J. A. (2006a). Suppressed oxytocin neuron responses to immune challenge in late pregnant rats: a role for endogenous opioids. Eur. J. Neurosci. 23, 1241-1247.

Brunton, P. J., Bales, J., and Russell, J. A. (2006b). Neuroendocrine stress but not feeding responses to centrally administered neuropeptide $\mathrm{Y}$ are suppressed in pregnant rats. Endocrinology 147, 3737-3745.

Brussaard, A. B., and Herbison, A. E. (2000). Long-term plasticity of postsynaptic GABAA-receptor function in the adult brain: insights from the oxytocin neurone. Trends Neurosci. 23, 190-195.

Bukstein, O. (2008). Substance abuse in patients with attentiondeficit/hyperactivity disorder. Medscape J. Med. 10, 24.

Burton, C. L., Chatterjee, D., ChatterjeeChakraborty, M., Lovic, V., Grella, S. L., Steiner, M., and Fleming, A. S. (2007). Prenatal restraint stress and motherless rearing disrupts expression of plasticity markers and stressinduced corticosterone release in adult female Sprague-Dawley rats. Brain Res. 1158, 28-38.

Campbell, J. C., Dunn, C. P., Nayak, R. R., Cornateanu, R. J., and Kippin, T. E. (2010). Prenatal Stress Produces Sex-Specific Effects on Alcohol Reinforcement and Intake in C57Bl/6J Mice. San Antonio, TX: Research Society on Alcoholism.

Campbell, J. C., Szumlinski, K. K., and Kippin, T. E. (2009). Contribution of early environmental stress to alcoholism vulnerability. Alcohol 43, 547-554.

Carboni, E., Barros, V. G., Ibba, M., Silvagni, A., Mura, C., and Antonelli, M. C. (2010). Prenatal restraint stress: an in vivo microdialysis study on catecholamine release in the rat prefrontal cortex. Neuroscience 168, 156-166.

Casada, J. H., and Roache, J. D. (2004). Neurosteroids in PTSD. International Society for Traumatic Stress Studies Annual Meeting, New Orleans, LA.

Chanrachakul, B., Broughton Pipkin, F., Warren, A. Y., Arulkumaran, S., and Khan, R. N. (2005). Progesterone enhances the tocolytic effect of ritodrine in isolated pregnant human myometrium. Am. J. Obstet Gynecol. 192, 458-463.

Coe, C. L., Kramer, M., Czéh, B., Gould, E., Reeves, A. J., Kirschbaum, C. and Fuchs, E. (2003). Prenatal stress diminishes neurogenesis in the dentate gyrus of juvenile rhesus monkeys. Biol. Psychiatry 54, 1025-1034. Concas, A., Follesa, P., Barbaccia, M. L., Purdy, R. H., and Biggio, G. (1999). Physiological modulation of GABA(A) receptor plasticity by progesterone metabolites. Eur. J. Pharmacol. 375, 225-235.

Concas, A., Mostallino, M. C., Porcu, P., Follesa, P., Barbaccia, M. L., Trabucchi, M., Purdy, R. H., Grisenti, P., and Biggio, G. (1998). Role of brain allopregnanolone in the plasticity of gamma-aminobutyric acid type A receptor in rat brain during pregnancy and after delivery. Proc. Natl. Acad. Sci. U.S.A. 95, 13284-13289.

Conrad, C. D., Grote, K. A., Hobbs, R. J., and Ferayorni, A. (2003). Sex differences in spatial and non-spatial Y-maze performance after chronic stress. Neurobiol. Learn. Mem. 79, 32-40.

Deminiere, J. M., Piazza, P. V., Guegan, G., Abrous, N., Maccari, S., Le Moal, M., and Simon, H. (1992). Increased locomotor response to novelty and 
propensity to intravenous amphetamine self-administration in adult offspring of stressed mothers. Brain Res. 586, 135-139.

DeRoche, V., Piazza, P. V., Deminiere, J. M., Le Moal, M., and Simon, H. (1993). Rats orally selfadminister corticosterone. Brain Res. 622, 315-320.

DeTurck, K. H., and Pohorecky, L. A. (1987). Ethanol sensitivity in rats: effect of prenatal stress. Physiol. Behav. 40, 407-410.

Devaud, L. L., Risinger, F. O., and Selvage, D. (2006). Impact of the hormonal milieu on the neurobiology of alcohol dependence and withdrawal. J. Gen. Psychol. 133, 337-356.

Diaz, R., Ogren, S. O., Blum, M., and Fuxe, K. (1995). Prenatal corticosterone increases spontaneous and d-amphetamine induced locomotor activity and brain dopamine metabolism in prepubertal male and female rats. Neuroscience 66, 467-473.

Djebaili, M., Guo, Q., Pettus, E. H., Hoffman, S. W., and Stein, D. G. (2005). The neurosteroids progesterone and allopregnanolone reduce cell death, gliosis, and functional deficits after traumatic brain injury in rats. $J$. Neurotrauma 22, 106-118.

Done, D. J., Crow, T. J., Johnstone, E. C., and Sacker, A. (1994). Childhood antecedents of schizophrenia and affective illness: social adjustment at ages 7 and 11. BMJ 309, 699-703.

Drago, F., Di Leo, F., and Giardina, L. (1999). Prenatal stress induces body weight deficit and behavioural alterations in rats: the effect of diazepam. Eur. Neuropsychopharmacol. 9, 239-245.

Ellermeier, W., and Westphal, W. (1995). Gender differences in pain ratings and pupil reactions to painful pressure stimuli. Pain 61, 435-439.

Ericsson, A., Kovács, K. J., and Sawchenko, P. E. (1994). A functional anatomical analysis of central pathways subserving the effects of interleukin-1 on stress-related neuroendocrine neurons. J. Neurosci. 14, 897-913.

Evans, S. M., and Foltin, R. W. (2006). Exogenous progesterone attenuates the subjective effects of smoked cocaine in women, but not in men. Neuropsychopharmacology 31, 659-674.

Evans, S. M., Haney, M., and Foltin, R. W. (2002). The effects of smoked cocaine during the follicular and luteal phases of the menstrual cycle in women. Psychopharmacology (Berl.) 159, 397-406.
Evans, S. M., and Levin, F. R. (2011). Response to alcohol in women: role of the menstrual cycle and a family history of alcoholism. Drug Alcohol Depend. 114, 18-30.

Facchinetti, F., Ottolini, F., Fazzio, M., Rigatelli, M., and Volpe, A. (2007). Psychosocial factors associated with preterm uterine contractions. Psychother. Psychosom. 76, 391-394.

Feltenstein, M. W., and See, R. E. (2007). Plasma progesterone levels and cocaine-seeking in freely cycling female rats across the estrous cycle. Drug Alcohol Depend. 89, 183-189.

Feltenstein, M. W., and See, R. E. (2008). The neurocircuitry of addiction: an overview. Br. J. Pharmacol. 154, 261-274.

Ferrini, M. G., Grillo, C. A., Piroli, G., de Kloet, E. R., and De Nicola, A. F. (1997). Sex difference in glucocorticoid regulation of vasopressin mRNA in the paraventricular hypothalamic nucleus. Cell. Mol. Neurobiol. 17, 671-686.

Finn, D. A., Beadles-Bohling, A. S., Beckley, E. H., Ford, M. M., Gililland, K. R., Gorin-Meyer, R. E., and Wiren, K. M. (2006). A new look at the $5 \alpha-$ reductase inhibitor finasteride. CNS Drug Rev. 12, 53-76.

Finn, D. A., Mark, G. P., Fretwell, A. M., Gililland-Kaufman, K. R., Strong, M. N., and Ford, M. M. (2008). Reinstatement of ethanol and sucrose seeking by the neurosteroid allopregnanolone in C57BL/6 mice. Psychopharmacology (Berl.) 201, 423-433.

Finn, D. A., Sinnott, R. S., Ford, M. M., Long, S. L., Tanchuck, M. A., and Phillips, T. J. (2004). Sex differences in the effect of ethanol injection and consumption on brain allopregnanolone levels in C57BL/6 mice. Neuroscience 123, 813-819.

Franklin, T. R., Napier, K., Ehrman, R., Gariti, P., O’Brien, C. P., and Childress, A. R. (2004). Retrospective study: influence of menstrual cycle on cue-induced cigarette craving. Nicotine Tob. Res. 6, 171-175.

Freeman, E. W., Frye, C. A., Rickels, K., Martin, P. A., and Smith, S. S. (2002). Allopregnanolone levels and symptom improvement in severe premenstrual syndrome. J. Clin. Psychopharmacol. 22, 516-520.

Fride, E., Dan, Y., Gavish, M., and Weinstock, M. (1985). Prenatal stress impairs maternal behavior in a conflict situation and reduces hippocampal benzodiazepine receptors. Life Sci. 36, 2103-2109.

Frisone, D. F., Frye, C. A., and Zimmerberg, B. (2002). Social isolation stress during the third week of life has age-dependent effects on spatial learning in rats. Behav. Brain Res. $128,153-160$.

Frye, C. A. (2009). "Neurosteroids-from basic research to clinical perspectives," in Hormones/Behavior Relations of Clinical Importance, eds R. T. Rubin and D. W. Pfaff (San Diego: Academic Press), 395-416.

Frye, C. A., Babson, A., and Walf, A. A. (2007). Self-administration of $3 \alpha$-androstanediol increases locomotion and analgesia and decreases aggressive behavior of male hamsters. Pharmacol. Biochem. Behav. 86 415-421.

Frye, C. A., and Bayon, L. E. (1998). Seizure activity is increased in endocrine states characterized by decline in endogenous levels of the neurosteroid $3 \alpha, 5 \alpha$-THP. Neuroendocrinology 68, 272-280.

Frye, C. A., Bayon, L. E., Pursnani, N. K., and Purdy, R. H. (1998) The neurosteroids, progesterone and $3 \alpha, 5 \alpha$-THP, enhance sexual motivation, receptivity, and proceptivity in female rats. Brain Res. 808, 72-83.

Frye, C. A., and McCormick, C. M. (2000a). The neurosteroid, $3 \alpha$ androstanediol, prevents inhibitory avoidance deficits and pyknotic cells in the granule layer of the dentate gyrus induced by adrenalectomy in rats. Brain Res. 855, 166-170.

Frye, C. A., and McCormick, C. M. (2000b). Androgens are neuroprotective in the dentate gyrus of adrenalectomized female rats. Stress 3, 185-194.

Frye, C. A., and Orecki, Z. A. (2002). Prenatal stress alters reproductive responses of rats in behavioral estrus and paced mating of hormoneprimed rats. Horm. Behav. 42, 472-483.

Frye, C. A., Paris, J. J., and Rhodes, M. E. (2008). Estrogen is necessary for $5 \alpha$-pregnan-3 $\alpha$-ol-20-one $(3 \alpha, 5 \alpha-\mathrm{THP})$ infusion to the ventral tegmental area to facilitate social and sexual, but neither exploratory nor affective behavior of ovariectomized rats. Pharmacol. Biochem. Behav. 91, 261-270.

Frye, C. A., and Rhodes, M. E. (2006). Progestin concentrations are increased following paced mating in midbrain, hippocampus, diencephalon, and cortex of rats in behavioral estrus, but only in midbrain of diestrous rats. Neuroendocrinology 83, 336-347.

Frye, C. A., Rhodes, M. E., Petralia, S. M., Walf, A. A., Sumida, K., and Edinger, K. L. (2006a). $3 \alpha-$ hydroxy- $5 \alpha$-pregnan-20-one in the midbrain ventral tegmental area mediates social, sexual, and affective behaviors. Neuroscience 138, 1007-1014.

Frye, C. A., Rhodes, M. E., Raol, Y. H., and Brooks-Kayal, A. R. (2006b). Early postnatal stimulation alters pregnane neurosteroids in the hippocampus. Psychopharmacology (Berl.) 186, 343-350.

Frye, C. A., and Walf, A. A. (2004) Hippocampal $3 \alpha, 5 \alpha$-THP may alter depressive behavior of pregnant and lactating rats. Pharmacol. Biochem. Behav. 78, 531-540.

Frye, C. A., and Walf, A. A. (2008a). Effects of progesterone administration and APPswe+PSEN1Deltae9 mutation for cognitive performance of mid-aged mice. Neurobiol. Learn. Mem. 89, 17-26.

Frye, C. A., and Walf, A. A. (2008b). Membrane actions of progestins at dopamine type 1-like and GABA(A) receptors involve downstream signal transduction pathways. Steroids 73, 906-913.

Frye, C. A., and Walf, A. A. (2009). Progesterone reduces depressionlike behavior in a murine model of Alzheimer's Disease. Age (Dordr.) 31, 143-153.

Frye, C. A., Walf, A. A., and Sumida, K. (2004). Progestins' actions in the VTA to facilitate lordosis involve dopamine-like type 1 and 2 receptors. Pharmacol. Biochem. Behav. 78, 405-418.

Frye, C. A., and Wawrzycki, J. (2003). Effect of prenatal stress and gonadal hormone condition on depressive behaviors of female and male rats. Horm. Behav. 44, 319-326.

Fumagalli, F., Bedogni, F., Perez, J., Racagni, G., and Riva, M. A. (2004) Corticostriatal brain-derived neurotrophic factor dysregulation in adult rats following prenatal stress. Eur. J. Neurosci. 20, 1348-1354.

Fumagalli, F., Bedogni, F., Slotkin, T. A., Racagni, G., and Riva, M. A. (2005). Prenatal stress elicits regionally selective changes in basal FGF-2 gene expression in adulthood and alters the adult response to acute or chronic stress. Neurobiol. Dis. 20, 731-737.

Galea, L. A., McEwen, B. S., Tanapat, P., Deak, T., Spencer, R. L., and Dhabhar, F. S. (1997). Sex differences in dendritic atrophy of CA3 pyramidal neurons in response to chronic restraint stress. Neuroscience 81, 689-697.

Gallop, R. J., Crits-Christoph, P., Ten Have, T. R., Barber, J. P., Frank, A., Griffin, M. L., and Thase, M. E. (2007). Differential transitions 
between cocaine use and abstinence for men and women. J. Consult. Clin. Psychol. 75, 95-103.

Gass, J. T., and Olive, M. F. (2008). Glutamatergic substrates of drug addiction and alcoholism. Biochem. Pharmacol. 75, 218-265.

George, O., and Koob, G. F. (2010). Individual differences in prefrontal cortex function and the transition from drug use to drug dependence. Neurosci. Biobehav. Rev. 35, 232-247.

Gerardin, D. C., Pereira, O. C., Kempinas, W. G., Florio, J. C., Moreira, E. G., and Bernardi, M. M. (2005). Sexual behavior, neuroendocrine, and neurochemical aspects in male rats exposed prenatally to stress. Physiol. Behav. 84, 97-104.

Gilbert Evans, S. E., Ross, L. E., Sellers, E. M., Purdy, R. H., and Romach, M. K. (2005). 3 $\alpha$-reduced neuroactive steroids and their precursors during pregnancy and the postpartum period. Gynecol. Endocrinol. 21, 268-279.

Girdler, S. S., and Klatzkin, R. (2007). Neurosteroids in the context of stress: implications for depressive disorders. Pharmacol. Ther. 116, 125-139.

Gitau, R., Fisk, N. M., Teixeira, J. M., Cameron, A., and Glover, V. (2001). Fetal hypothalamicpituitary-adrenal stress responses to invasive procedures are independent of maternal responses. J. Clin. Endocrinol. Metab. 86, 104-109.

Giurgescu, C. (2009). Are maternal cortisol levels related to preterm birth? J. Obstet. Gynecol. Neonatal. Nurs. 38, 377-390.

Givalois, L., Gaillet, S., Mekaouche, M., Ixart, C., Bristow, A. F., Siaud, P., Szafarczyk, A., Malaval, F., Assenmacher, I., and Barbanel, G. (1995). Deletion of the ventral noradrenergic bundle obliterates the early ACTH response after systemic LPS, independently from the plasma IL- $1 \beta$ surge. Endocrine 3, 481-485.

Goldenberg, R. L., Culhane, J. F., Iams, J. D., and Romero, R. (2008). Epidemiology and causes of preterm birth. Lancet 371, 75-84.

Goodman, A. (2008). Neurobiology of addiction. An integrative review. Biochem. Pharmacol. 75, 266-322.

Gracias, C. R., Freeman, E. W., Sammel, M. D., Lin, H., Sheng, L., and Frye, C.A. (2009). Allopregnanolone levels before and after selective serotonin reuptake inhibitor treatment of premenstrual symptoms. J. Clin. Psychopharmacol. 29, 403-405.
Green, K. L., Azarov, A. V., Szeliga, K. T., Purdy, R. H., and Grant, K. A. (1999). The influence of menstrual cycle phase on sensitivity to ethanol-like discriminative stimulus effects of GABA(A)-positive modulators. Pharmacol. Biochem. Behav. 64, 379-383.

Grobin, A. C., and Morrow, A. L. (2001). 3 3 $\alpha$-hydroxy-5 $\alpha$-pregnan20-one levels and GABA(A) receptor-mediated $36 \mathrm{Cl}(-)$ flux across development in rat cerebral cortex. Brain Res. Dev. Brain Res. 131, 31-39.

Gué, M., Bravard, A., Meunier, J., Veyrier, R., Gaillet, S., Recasens, M., and Maurice, T. (2004). Sex differences in learning deficits induced by prenatal stress in juvenile rats. Behav. Brain Res. 150, 149-157.

Haber, S. N., and Fudge, J. L. (1997). The primate substantia nigra and VTA: integrative circuitry and function. Crit. Rev. Neurobiol. 11, 323-342.

He, W. B., Zhao, M., Machida, T., and Chen, N. H. (2009). Effect of corticosterone on developing hippocampus: short-term and long-term outcomes. Hippocampus 19, 338-349.

Hecht, G. S., Spear, N. E., and Spear, L. P. (1999). Changes in progressive ratio responding for intravenous cocaine throughout the reproductive process in female rats. Dev. Psychobiol. 35, 136-145.

Helms, C. M., and Grant, K. A. (2011). The effect of age on the discriminative stimulus effects of ethanol and its $\mathrm{GABA}(\mathrm{A})$ receptor mediation in cynomolgus monkeys. Psychopharmacology (Berl.) 216, 333-343.

Henry, C., Guegant, G., Cador, M., Arnauld, E., Arsaut, J., Le Moal, M., and Demotes-Mainard, J. (1995). Prenatal stress in rats facilitates amphetamine-induced sensitization and induces long-lasting changes in dopamine receptors in the nucleus accumbens. Brain Res. 685, 179-186.

Herman, J. P., Prewitt, C. M., and Cullinan, W. E. (1996). Neuronal circuit regulation of the hypothalamopituitary-adrenocortical stress axis. Crit. Rev. Neurobiol. 10, 371-394.

Hermus, A. R., and Sweep, C. G. (1990). Cytokines and the hypothalamicpituitary-adrenal axis. J. Steroid Biochem. Mol. Biol. 37, 867-871.

Hinojosa-Laborde, C., Chapa, I., Lange, D., and Haywood, J. R. (1999). Gender differences in sympathetic nervous system regulation. Clin. Exp. Pharmacol. Physiol. 26, 122-126.

Horvitz, J. C. (2000). Mesolimbocortical and nigrostriatal dopamine responses to salient non-reward events. Neuroscience 96, 651-656.

Howell, A. N., Leyro, T. M., Hogan, J., Buckner, J. D., and Zvolensky, M. J. (2010). Anxiety sensitivity, distress tolerance, and discomfort intolerance in relation to coping and conformity motives for alcohol use and alcohol use problems among young adult drinkers. Addict. Behav. 35, 1144-1147.

Huizink, A. C., Mulder, E. J., and Buitelaar, J. K. (2004). Prenatal stress and risk for psychopathology: specific effects or induction of general susceptibility? Psychol. Bull. 130, 115-142.

Huttunen, M. O., and Niskanen, P. (1978). Prenatal loss of father and psychiatric disorders. Arch. Gen. Psychiatry 35, 429-431.

Ikemoto, S., and Panksepp, J. (1999). The role of nucleus accumbens dopamine in motivated behavior: a unifying interpretation with special reference to reward-seeking. Brain Res. Brain Res. Rev. 31, 6-41.

Iswari, S., Colas, A. E., and Karavolas, H. J. (1986). Binding of $5 \alpha$-dihydroprogesterone and other progestins to female rat anterior pituitary nuclear extracts. Steroids 47, 189-203.

Janis, G. C., Devaud, L. L., Mitsuyama, H., and Morrow, A. L. (1998). Effects of chronic ethanol consumption and withdrawal on the neuroactive steroid $3 \alpha$-hydroxy- $5 \alpha$-pregnan-20one in male and female rats. Alcohol. Clin. Exp. Res. 22, 2055-2061.

Jezová, D., Juránková, E., Mosnárová, A., Kriska, M., and Skultétyová, I. (1996). Neuroendocrine response during stress with relation to gender differences. Acta Neurobiol. Exp. (Wars) 56, 779-785

Johnson, R. W., Gheusi, G., Segreti, S., Dantzer, R., and Kelley, K. W. (1997). C3H/HeJ mice are refractory to lipopolysaccharide in the brain. Brain Res. 752, 219-226.

Johnstone, H. A., Wigger, A., Douglas, A. J., Neumann, I. D., Landgraf, R., Seckl, J. R., and Russell, J. A. (2000). Attenuation of hypothalamic-pituitary-adrenal axis stress responses in late pregnancy: changes in feedforward and feedback mechanisms. J. Neuroendocrinol. 12, 811-822.

Jutapakdeegul, N., Afadlal, S., Polaboon, N., Phansuwan-Pujito, P., and Govitrapong, P. (2010). Repeated restraint stress and corticosterone injections during late pregnancy alter GAP-43 expression in the hippocampus and prefrontal cortex of rat pups. Int. J. Dev. Neurosci. 28, 83-90.

Kalivas, P. W., Lalumiere, R. T., Knackstedt, L., and Shen, $\mathrm{H}$. (2009). Glutamate transmission in addiction. Neuropharmacology 56, 169-173.

Kehoe, P., Mallinson, K., McCormick, C. M., and Frye, C. A. (2000). Central allopregnanolone is increased in rat pups in response to repeated, short episodes of neonatal isolation. Brain Res. Dev. Brain Res. 124, 133-136.

Kelley, A. E. and Berridge, K. C. (2002). The neuroscience of natural rewards: relevance to addictive drugs. J. Neurosci. 22, 3306-3311.

Kellogg, C. K., and Frye, C. A. (1999). Endogenous levels of $5 \alpha$-reduced progestins and androgens in fetal vs. adult rat brains. Dev. Brain Res. 115, 17-24.

Kerstjens, J. M., de Winter, A. F., Bocca-Tjeertes, I. F., Ten Vergert, E. M., Reijneveld, S. A., and Bos, A. F. (2011). Developmental delay in moderately preterm-born children at school entry. J. Pediatr. 159, 92-98.

Keshet, G. I., and Weinstock, M. (1995). Maternal naltrexone prevents morphological and behavioral alterations induced in rats by prenatal stress. Pharmacol. Biochem. Behav. 50, 413-419.

King, C. R. (2011). A novel embryological theory of autism causation involving endogenous biochemicals capable of initiating cellular gene transcription: a possible link between twelve autism risk factors and the autism 'epidemic'. Med. Hypotheses 76, 653-660.

Kippin, T. E., Cain, S. W., Maszum, Z., and Ralph, M. M. (2004) Neural stem cells show bidirectional experience-dependent plasticity in the perinatal mammalian brain. $J$. Neurosci. 24, 2832-2836.

Kippin, T. E., Szumlinski, K. K., Kapasova, Z., Rezner, B., and See, R. E. (2008). Prenatal stress enhances responsiveness to cocaine. Neuropsychopharmacology 33, 769-782.

Kitraki, E., Kremmyda, O., Youlatos, D., Alexis, M. N., and Kittas, C. (2004). Gender-dependent alterations in corticosteroid receptor status and spatial performance following 21 days of restraint stress. $\mathrm{Neu}$ roscience $125,47-55$.

Klatzkin, R. R., Morrow, A. L., Light, K. C., Pedersen, C. A., and Girdler, S. S. (2006). Histories of depression, allopregnanolone responses to 
stress, and premenstrual symptoms in women. Biol. Psychol. 71, 2-11.

Kleinhaus, K., Steinfeld, S., Balaban, J., Goodman, L., Craft, T. S., and Malaspina, D., Myers, M. M., and Moore, H. (2010). Effects of excessive glucocorticoid receptor stimulation during early gestation on psychomotor and social behavior in the rat. Dev. Psychobiol. 52, 121-132.

Koehl, M., Bjijou, Y., Le Moal, M., and Cador, M. (2000). Nicotine-induced locomotor activity is increased by preexposure of rats to prenatal stress. Brain Res. 882, 196-200.

Koehl, M., Lemaire, V., Le Moal, M., and Abrous, D. N. (2009). Agedependent effect of prenatal stress on hippocampal cell proliferation in female rats. Eur. J. Neurosci. 29, 635-640.

Kohtz, A. S., Paris, J. J., and Frye, C. A. (2010). Low doses of cocaine decrease, and high doses increase, anxiety-like behavior and brain progestogen levels among intact rats. Horm. Behav. 57, 474-480.

Koob, G. F., and Le Moal, M. (2001). Drug addiction, dysregulation of reward, and allostasis. Neuropsychopharmacology 24, 97-129.

Koob, G. F., and Volkow, N. D. (2010). Neurocircuitry of addiction. Neuropsychopharacology 35, 217-238.

Kraszpulski, M., Dickerson, P. A., and Salm, A. K. (2006). Prenatal stress affects the developmental trajectory of the rat amygdala. Stress 9, 85-95.

Kroll, J. L. (2007). New directions in the conceptualization of psychotic disorders. Curr. Opin. Psychiatry 20, 573-577.

Lapish, C. C., Seamans, J. K., and Chandler, L. J. (2006). Glutamatedopamine cotransmission and reward processing in addiction. Alcohol. Clin. Exp. Res. 30, 1451-1465.

Larsen, E. B., Anker, J. J., Gliddon, L. A., Fons, K. S., and Carroll, M. E. (2007). Effects of estrogen and progesterone on the escalation of cocaine self-administration in female rats during extended access. Exp. Clin. Psychopharmacol. 15, 461-471.

Latendresse, G. (2009). The interaction between chronic stress and pregnancy: preterm birth from a biobehavioral perspective. J. Midwifery Womens Health 54, 8-17.

Lemaire, V., Koehl, M., Le Moal, M., and Abrous, D. N. (2000). Prenatal stress produces learning deficits associated with an inhibition of neurogenesis in the hippocampus. Proc. Natl. Acad. Sci. U.S.A. 97, 11032-11037.
Li, H., Li, Q. H., Zhu, Z. L., Chen, R., Cheng, D. X., Cai, Q., Jia, N., and Song, L. (2007). Prenatal restraint stress decreases neurogranin expression in rat offspring hippocampus. Sheng Li Xue Bao 59, 299-304.

Lind, A., Korkman, M., Lehtonen, L., Lapinleimu, H., Parkkola, R., Matomäki, J., Haataja, L., and PIPARI Study Group. (2011). Cognitive and neuropsychological outcomes at 5 years of age in preterm children born in the 2000s. Dev. Med. Child Neurol. 53, 256-362.

Lodygensky, G. A., Vasung, L., Sizonenko, S. V., and Hüppi, P. S. (2010). Neuroimaging of cortical development and brain connectivity in human newborns and animal models. J. Anat. 217, 418-428.

Ma, S., Shipston, M. J., Morilak, D., and Russell, J. A. (2005). Reduced hypothalamic vasopressin secretion underlies attenuated adrenocorticotropin stress responses in pregnant rats. Endocrinology 146, 1626-1637.

Majewska, M. D., Harrison, N. L., Schwartz, R. D., Barker, J. L., and Paul, S. M. (1986). Steroid hormone metabolites are barbituratelike modulators of the GABA receptor. Science 232, 1004-1007.

Manji, H. K., Drevets, W. C., and Charney, D. S. (2001). The cellular neurobiology of depression. Nat. Med. 7, 541-547.

Mann, K., Ackermann, K., Croissant, B., Mundle, G., Nakovics, H., and Diehl, A. (2005). Neuroimaging of gender differences in alcohol dependence: are women more vulnerable? Alcohol. Clin. Exp. Res. 29, 896-901.

Martinez-Tellez, R. I., HernandezTorres, E., Gamboa, C., and Flores, G. (2009). Prenatal stress alters spine density and dendritic length of nucleus accumbens and hippocampus neurons in rat offspring. Synapse 63, 794-804.

Marx, C. E., Stevens, R. D., Shampine, L. J., Uzunova, V., Trost, W. T., Butterfield, M. I., Massing, M. W., Hamer, R. M., Morrow, A. L., and Lieberman, J. A. (2006). Neuroactive steroids are altered in schizophrenia and bipolar disorder: relevance to pathophysiology and therapeutics. Neuropsychopharmacology 31, 1249-1263.

Matthews, S. G., Owen, D., Banjanin, S., and Andrews, M. H. (2002). Glucocorticoids, hypothalamo-pituitaryadrenal (HPA) development, and life after birth. Endocr. Res. 28, 709-718.

McArthur, S., McHale, E., Dalley, J. W., Buckingham, J. C., and
Gillies, G. E. (2005). Altered mesencephalic dopaminergic populations in adulthood as a consequence of brief perinatal glucocorticoid exposure. J. Neuroendocrinol. 17, 475-482.

McBride, W. J., and Li, T. K. (1998). Animal models of alcoholism: neurobiology of high alcohol-drinking behavior in rodents. Crit. Rev. Neurobiol. 12, 339-369.

McCormick, C. M., Kehoe, P., Mallinson, K., Cecchi, L., and Frye, C. A. (2002). Neonatal isolation alters stress hormone and mesolimbic dopamine release in juvenile rats. Pharmacol. Biochem. Behav. 73, 77-85.

McCormick, C. M., and Mathews, I. Z. (2007). HPA function in adolescence: role of sex hormones in its regulation and the enduring consequences of exposure to stressors. Pharmacol. Biochem. Behav. 86, 220-233.

McFadden, L. M., Paris, J. J., Mitzelfelt, M. S., McDonough, S., Frye, C. A., and Matuszewich, L. (2011). Sexdependent effects of chronic unpredictable stress in the water maze. Physiol. Behav. 102, 266-275.

Meerts, S. H. and Clark, A. S. (2007). Female rats exhibit a conditioned place preference for nonpaced mating. Horm. Behav. 51, 89-94.

Mello, N. K., Mendelson, J. H., and Palmieri, S. L. (1987). Cigarette smoking by women: interactions with alcohol use. Psychopharmacology (Berl.) 93, 8-15.

Mellon, S. H., Gong, W., and Schonemann, M. D. (2008). Endogenous and synthetic neurosteroids in treatment of Niemann-Pick type C disease. Brain Res. Rev. 57, 410-420.

Michelsen, K. A., van den Hove, D. L. Schmitz, C., Segers, O., Prickaerts, J., and Steinbusch, H. W. (2007). Prenatal stress and subsequent exposure to chronic mild stress influence dendritic spine density and morphology in the rat medial prefrontal cortex. BMC Neurosci. 8, 107. doi:10.1186/1471-2202-8-107

Mizoguchi, K., Kunishita, T., Chui, D. H., and Tabira, T. (1992). Stress induces neuronal death in the hippocampus of castrated rats. $\mathrm{Neu}$ rosci. Lett. 138, 157-160.

Morgan, K. N., Thayer, J. E., and Frye, C. A. (1999). Prenatal stress suppresses rat pup ultrasonic vocalization and myoclonic twitching in response to separation. Dev. Psychobiol. 34, 205-215.

Morley-Fletcher, S., Puopolo, M., Gentili, S., Gerra, G., Macchia,
T., and Laviola, G. (2004). Prenatal stress affects 3,4methylenedioxymethamphetamine pharmacokinetics and druginduced motor alterations in adolescent female rats. Eur. J. Pharmacol. 489, 89-92.

Morrow, A. L., VanDoren, M. J., Fleming, R., and Penland, S. (2001). Ethanol and neurosteroid interactions in the brain. Int. Rev. Neurobiol. 46, 349-377.

Morton, W. A. (1999). Cocaine and psychiatric symptoms. Prim. Care Companion J. Clin. Psychiatry 1, 109-113.

Murmu, M. S., Salomon, S., Biala, Y., Weinstock, M., Braun, K., and Bock, J. (2006). Changes of spine density and dendritic complexity in the prefrontal cortex in offspring of mothers exposed to stress during pregnancy. Eur. J. Neurosci. 24, 1477-1487.

Nestler, E. J., and Carlezon, W. A. Jr. (2006). The mesolimbic dopamine reward circuit in depression. Biol. Psychiatry 59, 1151-1159.

Nyberg, S., Andersson, A., Zingmark, E., Wahlström, G., Bäckström, T., and Sundström-Poromaa, I. (2005). The effect of a low dose of alcohol on allopregnanolone serum concentrations across the menstrual cycle in women with severe premenstrual syndrome and controls. Psychoneuroendocrinology 30, 892-901.

Odagiri, K., Abe, H., Kawagoe, C., Takeda, R., Ikeda, T., Matsuo, H., Nonaka, H., Ebihara, K., Nishimori, T., Ishizuka, Y., Hashiguchi, H., and Ishida, Y. (2008). Psychological prenatal stress reduced the number of BrdU immunopositive cells in the dorsal hippocampus without affecting the open field behavior of male and female rats at one month of age. Neurosci. Lett. 446, 25-29.

Ohkawa, T. (1987). Sexual differentiation of social play and copulatory behavior in prenatally stressed male and female offspring of the rat: the influence of simultaneous treatment by tyrosine during exposure to prenatal stress. Nippon Naibunpi Gakkai Zasshi 63, 823-835.

Paredes, R. G., and Vazquez, B. (1999). What do female rats like about sex? Paced mating. Behav. Brain Res. 105, 117-127.

Paintlia, M. K., Paintlia, A. S., Singh, A. K., and Singh, I. (2008). Attenuation of lipopolysaccharideinduced inflammatory response and phospholipids metabolism at the feto-maternal interface by N-acetyl cysteine. Pediatr. Res. 64 334-339. 
Paris, J. J., Brunton, P. J., Russell, J. A., Walf, A. A., and Frye, C. A. (2011). Inhibition of $5 \alpha$-reductase activity in late pregnancy decreases gestational length and fecundity and impairs object memory and central progestogen milieu of juvenile rat offspring. J. Neuroendocrinol. doi: 10.1111/j.1365-2826.2011.02219.x.

Paris, J. J., and Frye, C. A. (2008). Estrous cycle, pregnancy, and parity enhance performance of rats in object recognition or object placement tasks. Reproduction 136, 105-115.

Paris, J. J., and Frye, C. A. (2009). Alcohol dose-dependently enhances $3 \alpha-$ androstanediol formation in frontal cortex of male rats concomitant with aggression. Open Neuropsychopharmacol. J. 2, 1-10.

Paris, J. J., and Frye, C. A. (2011a). Juvenile offspring of rats exposed to restraint stress in late gestation have impaired cognitive performance and dysregulated progestogen formation. Stress 14, 23-32.

Paris, J. J., and Frye, C. A. (2011b). Gestational exposure to variable stressors produces decrements in cognitive and neural development of juvenile male and female rats. Curr. Top. Med. Chem. 11, 1706-1713.

Patchev, V. K., and Almeida, O. F. (1996). Gonadal steroids exert facilitating and "buffering" effects on glucocorticoid-mediated transcriptional regulation of corticotropinreleasing hormone and corticosteroid receptor genes in rat brain. $J$. Neurosci. 16, 7077-7084.

Patchev, V. K., Hassan, A. H., Holsboer, D. F., and Almeida, O. F. (1996). The neurosteroid tetrahydroprogesterone attenuates the endocrine response to stress and exerts glucocorticoid-like effects on vasopressin gene transcription in the rat hypothalamus. Neuropsychopharmacology 15, 533-540.

Patchev, V. K., Shoaib, M., Holsboer, F., and Almeida, O. F. (1994). The neurosteroid tetrahydroprogesterone counteracts corticotropin-releasing hormone-induced anxiety and alters the release and gene expression of corticotropinreleasing hormone in the rat hypothalamus. Neuroscience 62 , 265-271.

Pierucci-Lagha, A., Covault, J., Feinn, R., Khisti, R. T., Morrow, A. L., Marx, C. E., Shampine, L. J., and Kranzler, H. R. (2006). Subjective effects and changes in steroid hormone concentrations in humans following acute consumption of alcohol. Psychopharmacology (Berl.) 186, 451-461.
Poling, J., Kosten, T. R., and Sofuoglu, M. (2007). Treatment outcome predictors for cocaine dependence. $A m$. J. Drug Alcohol Abuse 33, 191-206.

Poltyrev, T., Keshet, G. I., Kay, G., and Weinstock, M. (1996). Role of experimental conditions in determining differences in exploratory behavior of prenatally stressed rats. Dev. Psychobiol. 29, 453-462.

Purdy, R. H., Morrow, A. L., Moore, P. H. Jr., and Paul, S. M. (1991). Stressinduced elevations of gammaaminobutyric acid type A receptoractive steroids in the rat brain. Proc. Natl. Acad. Sci. U.S.A. 88, 4553-4557.

Quinones-Jenab, V., Minerly, A. C., Niyomchia, T., Akahvan, A., Jenab, S., and Frye, C. A. (2008). Progesterone and allopregnanolone are induced by cocaine in serum and brain tissues of male and female rats. Pharmacol. Biochem. Behav. 89, 292-297.

Rasmusson, A. M., Pinna, G., Paliwal, P., Weisman, D., Gottschalk, C., Charney, D., Krystal, J., and Guidotti, A. (2006). Decreased cerebrospinal fluid allopregnanolone levels in women with posttraumatic stress disorder. Biol. Psychiatry 60, 704-713.

Reed, S. C., Evans, S. M., Bedi, G., Rubin, E., and Foltin, R. W. (2011). The effects of oral micronized progesterone on smoked cocaine selfadministration in women. Horm. Behav. 59, 227-235.

Rhodes, M. E., McCormick, C. M., and Frye, C. A. (2004). $3 \alpha, 5 \alpha$-THP mediates progestins' effects to protect against adrenalectomy-induced cell death in the dentate gyrus of female and male rats. Pharmacol. Biochem. Behav. 78, 505-512.

Rhodes, M. E., and Rubin, R. T. (1999). Functional sex differences ('sexual diergism') of central nervous system cholinergic systems, vasopressin, and hypothalamic-pituitary-adrenal axis activity in mammals: a selective review. Brain Res. Brain Res. Rev. 30, 135-152.

Robbins, S. J., Ehrman, R. N., Childress, A. R., and O'Brien, C. P. (1999). Comparing levels of cocaine cue reactivity in male and female outpatients. Drug Alcohol Depend. 53, 223-230.

Rodrigues, T., Rocha, L., and Barros, H. (2008). Physical abuse during pregnancy and preterm delivery. Am. J. Obstet. Gynecol. 198, 171.e1-e6.

Rohleder, N., Schommer, N. C., Hellhammer, D. H., Engel, R., and Kirschbaum, C. (2001). Sex differences in glucocorticoid sensitivity of proinflammatory cytokine production after psychosocial stress. Psychosom. Med. 63, 966-972.

Rubin, E., Aharonovich, E., Bisaga, A. Levin, F. R., Raby, W. N., and Nunes, E. V. (2007). Early abstinence in cocaine dependence: influence of comorbid major depression. Am. J. Addict. 16, 283-290.

Russell, J. A., Leng, G., and Douglas, A. J. (2003). The magnocellular oxytocin system, the fount of maternity: adaptations in pregnancy. Front. Neuroendocrinol. 24, 27-61.

Ryan, M. A., Jacobson, I. G., Sevick, C. J., Smith, T. C., Gumbs, G. R., Conlin, A. M., and United States Department of Defense Birth and Infant Health Registry. (2011). Health outcomes among infants born to women deployed to United States military operations during pregnancy. Birth Defects Res. A Clin. Mol. Teratol. 91, 117-124.

Salamone, J. D., Correa, M., Farrar, A. M., Nunes, E. J., and Pardo, M. (2009). Dopamine, behavioral economics, and effort. Front. Behav. Neurosci. 3:13. doi:10.3389/neuro.08.013.2009

Salm, A. K., Pavelko, M., Krouse, E. M. Webster, W., Kraszpulski, M., and Birkle, D. (2004). Lateral amygdaloid nucleus expansion in adult rats is associated with exposure to prenatal stress. Dev. Brain Res. 148, 159-167.

Sapolsky, R. M. (2001). Depression, antidepressants, and the shrinking hippocampus. Proc. Natl. Acad. Sci. U.S.A. 98, 12320-12322.

Sayeed, I., Guo, Q., Hoffman, S. W. and Stein, D. G. (2006). Allopregnanolone, a progesterone metabolite, is more effective than progesterone in reducing cortical infarct volume after transient middle cerebral artery occlusion. Ann. Emerg. Med. 47, 381-389.

Schlotz, W., and Phillips, D. I. (2009). Fetal origins of mental health: evidence and mechanisms. Brain Behav. Immun. 23, 905-916.

Schmitz, C., Rhodes, M. E., Bludau, M., Kaplan, S., Ong, P., Ueffing, I., Vehoff, J., Korr, H., and Frye, C. A. (2002). Depression: reduced number of granule cells in the hippocampus of female, but not male, rats due to prenatal restraint stress. Mol. Psychiatry 7, 810-813.

Schoenfeld, T. J., and Gould, E. (2011). Stress, stress hormones, and adult neurogenesis. Exp. Neurol. doi:10.1016/j.expneurol.2011.01.008

Schuckit, M. A. (2009). An overview of genetic influences in alcoholism. $J$. Subst. Abuse Treat. 36, S5-S14.

Seckl, J. R., and Meaney, M. J. (2004). Glucocorticoid programming. Ann. N. Y. Acad. Sci. 1032, 63-84.
Secoli, S. R., and Teixeira, N. A. (1998). Chronic prenatal stress affects development and behavioral depression in rats. Stress 2, 273-280.

Segarra, A. C., Agosto-Rivera, J. L., Febo, M., Lugo-Escobar, N., MenéndezDelmestre, R., Puig-Ramos, A., and Torres-Diaz, Y. M. (2009). Estradiol: a key biological substrate mediating the response to cocaine in female rats. Horm. Behav. 58, 33-43.

Serra, M., Sanna, E., Mostallino, M. C., and Biggio, G. (2007). Social isolation stress and neuroactive steroids. Eur. Neuropsychopharmacol. 17, 1-11.

Silvagni, A., Barros, V. G., Mura, C., Antonelli, M. C., and Carboni, E. (2008). Prenatal restraint stress differentially modifies basal and stimulated dopamine and noradrenaline release in the nucleus accumbens shell: an 'in vivo' microdialysis study in adolescent and young adult rats. Eur. J. Neurosci. 28, 744-758.

Sinha, R., Fox, H., Hong, K. I., Sofuoglu, M., Morgan, P. T., and Bergquist, K. T. (2007). Sex steroid hormones, stress response, and drug craving in cocaine-dependent women: implications for relapse susceptibility. Exp. Clin. Psychopharmacol. 15, 445-452.

Sinnott, R. S., Mark, G. P., and Finn, D. A. (2002a). Reinforcing effects of the neurosteroid allopregnanolone in rats. Pharmacol. Biochem. Behav. 72, 923-929.

Sinnott, R. S., Phillips, T. J., and Finn, D. A. (2002b). Alteration of voluntary ethanol and saccharin consumption by the neurosteroid allopregnanolone in mice. Psychopharmacology (Berl.) 162, 438-447.

Snively, T. A., Ahijevych, K. L., Bernhard, L. A., and Wewers, M. E. (2000). Smoking behavior, dysphoric states and the menstrual cycle: results from single smoking sessions and the natural environment. Psychoneuroendocrinology 25, 677-691.

Sofuoglu, M., Babb, D. A., and Hatsukami, D. K. (2002). Effects of progesterone treatment on smoked cocaine response in women. Pharmacol. Biochem. Behav. 72, 431-435.

Sofuoglu, M., Dudish-Poulsen, S., Nelson, D., Pentel, P. R., and Hatsukami, D. K. (1999). Sex and menstrual cycle differences in the subjective effects from smoked cocaine in humans. Exp. Clin. Psychopharmacol. 7, 274-283.

Sofuoglu, M., Mitchell, E., and Kosten, T. R. (2004). Effects of progesterone treatment on cocaine responses in male and female cocaine users. Pharmacol. Biochem. Behav. 78, 699-705. 
Sofuoglu, M., and Sewell, R. A. (2009). Norepinephrine and stimulant addiction. Addict. Biol. 14, 119-219.

Son, G. H., Chung, S., Geum, D., Kang, S. S., Choi, W. S., Kim, K., and Choi, S. (2007). Hyperactivity and alteration of the midbrain dopaminergic system in maternally stressed male mice offspring. Biochem. Biophys. Res. Commun. 352, 823-829.

Sumida, K., Walf, A. A., and Frye, C. A. (2005). Progestin-facilitated lordosis of hamsters may involve dopaminelike type 1 receptors in the ventral tegmental area. Behav. Brain Res. 161, 1-7.

Sutker, P. B., Goist, K. C. Jr., and King, A. R. (1987). Acute alcohol intoxication in women: relationship to dose and menstrual cycle phase. Alcohol. Clin. Exp. Res. 11, 74-79.

Talge, N. M., Holzman, C., Wang, J., Lucia, V., Gardiner, J., and Breslau, N. (2010). Late-preterm birth and its association with cognitive and socioemotional outcomes at 6 years of age. Pediatrics 126, 1124-1131.

Thomas, M. B., Hu, M., Lee, T. M., Bhatnagar, S., and Becker, J. B. (2009). Sex-specific susceptibility to cocaine in rats with a history of prenatal stress. Physiol. Behav. 97, 270-277.

Tindell, A. J., Berridge, K. C., Zhang, J., Peciña, S., and Aldridge, J. W. (2005). Ventral pallidal neurons code incentive motivation: amplification by mesolimbic sensitization and amphetamine. Eur. J. Neurosci. 22, 2617-2634.

Torres, J. M., and Ortega, E. (2003). Alcohol intoxication increases allopregnanolone levels in female adolescent humans. Neuropsychopharmacology 28, 1207-1209.
Turnbull, A. V., Lee, S., and Rivier, C. (1998). Mechanisms of hypothalamic-pituitary-adrenal axis stimulation by immune signals in the adult rat. Ann. N. Y. Acad. Sci. 840, 434-443.

Turnbull, A. V., and Rivier, C. (1997). Corticotropin-releasing factor (CRF) and endocrine responses to stress: CRF receptors, binding protein, and related peptides. Proc. Soc. Exp. Biol. Med. 215, 1-10.

Turnbull, A. V., and Rivier, C. L. (1999). Sprague-Dawley rats obtained from different vendors exhibit distinct adrenocorticotropin responses to inflammatory stimuli. Neuroendocrinology 70, 186-195.

Uno, H., Tarara, R., Else, J. G., Suleman, M. A., and Sapolsky, R. M. (1989). Hippocampal damage associated with prolonged and fatal stress in primates. J. Neurosci. 9, 1705-1711.

Vallée, M., Mayo, W., Dellu, F., Le Moal, M., Simon, H., and Maccari, S. (1997). Prenatal stress induces high anxiety and postnatal handling induces low anxiety in adult offspring: correlation with stressinduced corticosterone secretion. $J$. Neurosci. 17, 2626-2636.

Van den Hove, D. L., Lauder, J. M., Scheepens, A., Prickaerts, J., Blanco, C. E., and Steinbusch, H. W. (2006). Prenatal stress in the rat alters 5HT1A receptor binding in the ventral hippocampus. Brain Res. 1090, 29-34.

Volkow, N. D., Wang, G. J., Fowler, J. S., Tomasi, D., Telang, F., and Baler, R. (2010). Addiction: decreased reward sensitivity and increased expectation sensitivity conspire to overwhelm the brain's control circuit. Bioessays 32, 748-755.
Wakshlak, A., and Weinstock, M. (1990). Neonatal handling reverses behavioral abnormalities induced in rats by prenatal stress. Physiol. Behav. 48, 289-292.

Walf, A. A., and Frye, C. A. (2007). Estradiol decreases anxiety behavior and enhances inhibitory avoidance and gestational stress produces opposite effects. Stress 10, 251-260.

Wang, J. M., Singh, C., Liu, L., Irwin, R. W., Chen, S., Chung, E. J., Thompson, R. F., and Brinton, R. D (2010). Allopregnanolone reverses neurogenic and cognitive deficits in mouse model of Alzheimer's disease. Proc. Natl. Acad. Sci. U.S.A. 107, 6498-6503.

Ward, I. L., and Stehm, K. E. (1991). Prenatal stress feminizes juvenile play patterns in male rats. Physiol. Behav. 50, 601-605.

Weinstock, M., and Fride, E. (1989). Alterations in behavioral and striatal dopamine asymmetries induced by prenatal stress. Pharmacol. Biochem. Behav. 32, 425-430.

Wise, R. A. (2004). Drive, incentive, and reinforcement: the antecedents and consequences of motivation. Nebr. Symp. Motiv. 50, 159-195.

Wortsman, J. (2002). Role of epinephrine in acute stress. Endocrinol. Metab. Clin. North Am. 31, 79-106.

Xiong, X., Harville, E. W., Mattison, D. R., Elkind-Hirsch, K., Pridjian, G., and Buekens, P. (2008). Exposure to Hurricane Katrina, posttraumatic stress disorder and birth outcomes. Am. J. Med. Sci. 336, 111-115.

Yawno, T., Hirst, J. J., Castillo-Melendez, M., and Walker, D. W. (2009). Role of neurosteroids in regulating cell death and proliferation in the late gestation fetal brain. Neuroscience $163,838-847$.

Yehuda, R., Bierer, L. M., Sarapas, C., Makotkine, I., Andrew, R., and Seckl, J. R. (2009). Cortisol metabolic predictors of response to psychotherapy for symptoms of PTSD in survivors of the World Trade Center attacks on September 11, 2001. Psychoneuroendocrinology 34, 1304-1313.

Zimmerberg, B., and Blaskey, L. G. (1998). Prenatal stress effects are partially ameliorated by prenatal administration of the neurosteroid allopregnanolone. Pharmacol. Biochem. Behav. 59, 819-827.

Conflict of Interest Statement: The authors declare that the research was conducted in the absence of any commercial or financial relationships that could be construed as a potential conflict of interest.

Received: 21 February 2011; accepted: 10 September 2011; published online: 17 October 2011.

Citation: Frye CA, Paris JJ, Osborne DM, Campbell JC and Kippin TE (2011) Prenatal stress alters progestogens to mediate susceptibility to sex-typical, stresssensitive disorders, such as drug abuse: a review. Front. Psychiatry 2:52. doi: 10.3389/fpsyt.2011.00052

This article was submitted to Frontiers in Child and Neurodevelopmental Psychiatry, a specialty of Frontiers in Psychiatry. Copyright (C) 2011 Frye, Paris, Osborne, Campbell and Kippin. This is an openaccess article subject to a non-exclusive license between the authors and Frontiers Media SA, which permits use, distribution and reproduction in other forums, provided the original authors and source are credited and other Frontiers conditions are complied with. 